\title{
¿ENSO Teleconnection to Eastern African Summer Rainfall in Global Climate Models: Role of the Tropical Easterly Jet 0
}

\author{
AmandeEP VASHISht, Benjamin ZaITCHIK, AND ANAND GNANADESIKAN \\ Department of Earth and Planetary Sciences, The Johns Hopkins University, Baltimore, Maryland
}

(Manuscript received 27 March 2020, in final form 3 August 2020)

\begin{abstract}
Global climate models (GCMs) are critical tools for understanding and projecting climate variability and change, yet the performance of these models is notoriously weak over much of tropical Africa. To improve this situation, process-based studies of African climate dynamics and their representation in GCMs are required. Here, we focus on summer rainfall of eastern Africa (SREA), which is crucial to the Ethiopian Highlands and feeds the flow of the Blue Nile River. The SREA region is highly vulnerable to droughts, with El Niño-Southern Oscillation (ENSO) being a leading cause of interannual rainfall variability. Adequate understanding and accurate representation of climate features that influence regional variability is an important but often neglected issue when evaluating models. We perform a process-based evaluation of GCMs, focusing on the upper-troposphere tropical easterly jet (TEJ), which has been hypothesized to link ENSO to SREA. We find that most models have an ENSO-TEJ coupling similar to observed, but the models diverge in their representation of TEJ-SREA coupling. Differences in the latter explain the majority $(80 \%)$ of variability in ENSO teleconnection simulation across the models. This is higher than the variance explained by rainfall coupling with the Somali jet $(44 \%)$ and African easterly jet (55\%). However, our diagnostics of the leading hypothesized mechanism in the models-variability in divergence in the TEJ exit region-are not consistent across models and suggest that a deeper understanding of the mechanisms of TEJ-precipitation coupling should be a priority for studies of climate variability and change in the region.
\end{abstract}

KEYWORDS: Africa; ENSO; Climate change; Climate variability; Model evaluation/performance

\section{Introduction}

Global climate models (GCMs) are highly valuable tools used to study past, present, and future climate all over the world (Kharin et al. 2013; Hemer et al. 2013; Fordham et al. 2012; Tierney et al. 2015; Siam and Eltahir 2017). However, their progress is limited over Africa (Randall et al. 2007; Flato et al. 2013; Rowell 2013; Watterson et al. 2014). A region of importance is eastern Africa, which is understudied and is highly vulnerable to climate variability and change (Bhattacharjee and Zaitchik 2015; Randall et al. 2007). GCMs show little consensus in seasonality, interannual variability, and teleconnections of precipitation in the region when compared to observational records, and this uncertainty undermines projections of future climate change for many models (Bhattacharjee and Zaitchik 2015). This means that projections based on a flat multimodel mean approach have limited value in climate adaptation, and it is imperative to evaluate these models for model improvement as well as to select "better" models for valuable climate information

¿ Denotes content that is immediately available upon publication as open access.

Supplemental information related to this paper is available at the Journals Online website: https://doi.org/10.1175/JCLI-D-200222.s1.

Corresponding author: Amandeep Vashisht, avashis3@jhu.edu
(Verdin et al. 2005; Rowell 2013; Jury 2015; Bhattacharjee and Zaitchik 2015; James et al. 2018).

Summertime (July-September) rainfall in eastern Africa (SREA) is greatest in the Ethiopian Highlands (Fig. 1a), a critical agricultural region that is also the headwaters region for the Blue Nile and other rivers of the eastern Nile Basin. Thus, it is vital for Blue Nile River flows (which contribute over $50 \%$ of flow in the mainstem Nile; Conway 2000) with major implications for transboundary water management of Ethiopia, Sudan, and Egypt (Berhane et al. 2014). SREA is prone to significant interannual variability (Gleixner et al. 2017), including damaging drought events that affect food security in Ethiopia and downstream regions. There is a large spread in the future rainfall projections of different models, which is not easily accounted for in analyses of historical model performance (Bhattacharjee and Zaitchik 2015). Furthermore, most projections of future climate change have focused on changes in mean rainfall, when variability may be an even more important factor for ecological and social impacts. Understanding the drivers of current variability and their representation in climate models, then, is an important and sometimes underappreciated research need.

Perhaps the most commonly known proximal driver of rainfall in the region is the seasonal migration of the intertropical convergence zone (ITCZ), the zone where the trade winds from the Northern and Southern Hemispheres converge locally to produce convection by ascent. During summer months, the ITCZ shifts north toward the basin, coinciding with the onset of the rainy season. During the summer rainy season moisture is brought into the region through low-level winds from southwesterlies and southeasterlies from the Atlantic and Indian 
a) Observ.

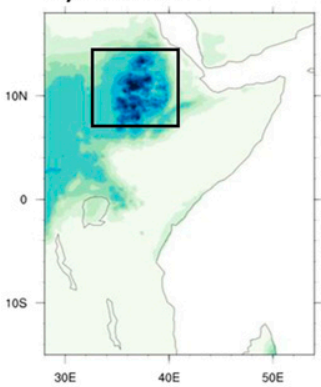

f) CNRM-CM5

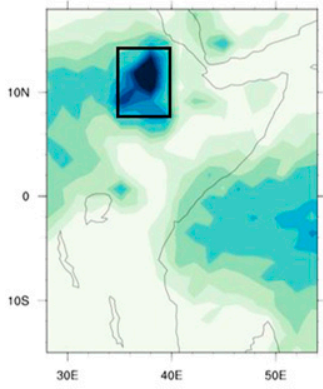

k) HadGEM2-ES b) CanESM2

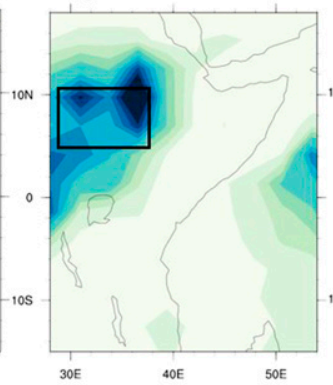

g) GFDL-CM3 c) $\mathrm{CCSM} 4$

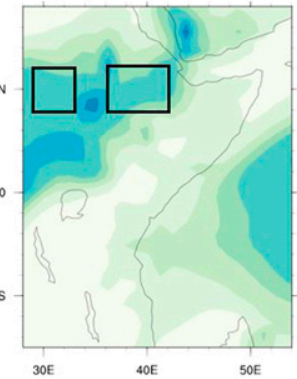

h) GFDL-ESM2M d) CESM

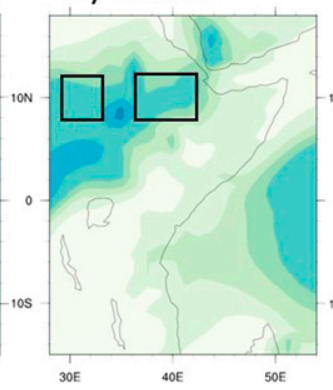

i) GFDL-ESM2G e) CMCC-CM

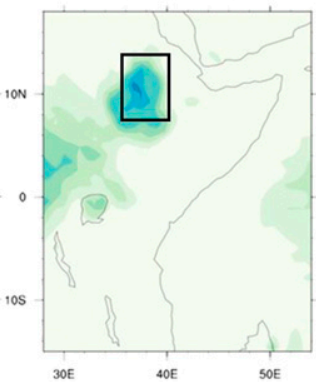

j) HadGEM2-CC
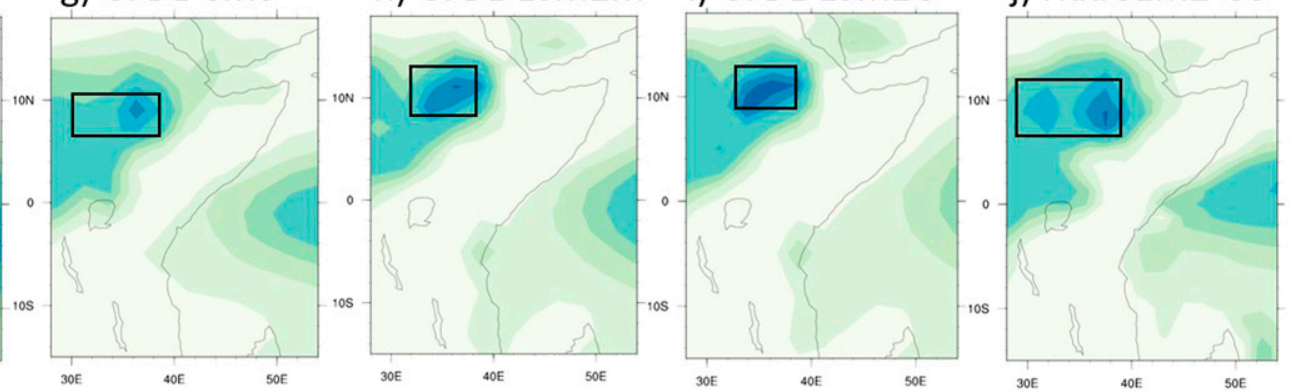

m) IPSL-CM5B-LR

n) MIROC5 o) MRI-CGCM3
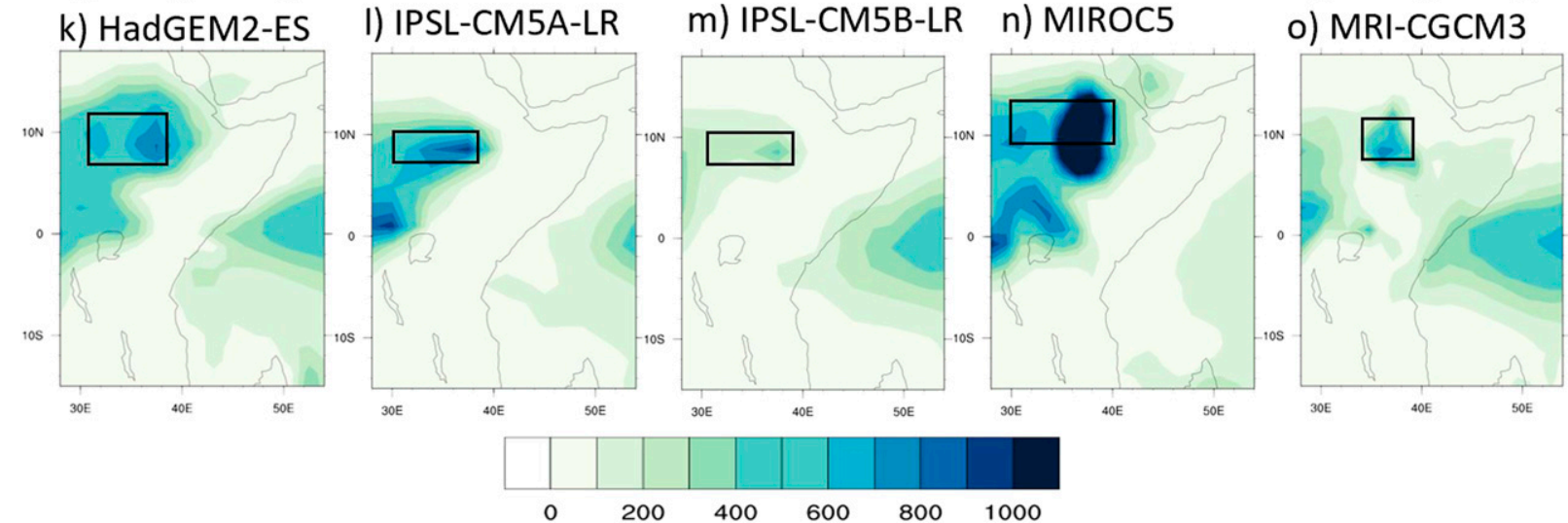

FIG. 1. JAS Precipitation climatology over eastern Africa (1950-90; $\mathrm{mm} \mathrm{yr}^{-1}$ ). Boxes are the regions of maximum summer rainfall, defined as summer rainfall of eastern Africa (SREA).

Ocean, as well as easterlies and northeasterlies that pass over the Red Sea and Mediterranean Sea (Conway 2000; Viste and Sorteberg 2013). The convective ascent is further fueled by orographic lift of converging moist air masses due to the highlands of Ethiopia (Slingo et al. 2005). A diverse array of largescale pressure centers, including the Arabian low, Saharan high, Mascarene high, and St. Helena high create pressure differences across broad regions resulting in low-level winds, including southerly flow into the region from the Somali jet and westerly winds from the Gulf of Guinea and across central and North Africa (Berhane et al. 2014). Alongside these low-level winds, upper- and middle-level jets also have associations with summer rainfall (Segele et al. 2009).

These atmospheric phenomena have been linked to variability in global and individual ocean basins, often with the intent of generating seasonal rainfall predictions (Gissila et al. 2004; Korecha and Barnston 2007; Nicholson 2014). Sea surface temperatures (SSTs) over the tropical Pacific Ocean associated with El Niño-Southern Oscillation (ENSO) have been found to be the single most powerful predictor of rainfall variability, with Atlantic and Indian Ocean teleconnections being weaker and of smaller spatial scale (Korecha and Barnston 2007). Diro et al. (2011a) showed that the Atlantic Ocean's influence may be somewhat stronger than that of the Indian Ocean, and Li et al. (2016) used the North Atlantic subtropical high to explain future (RCP4.5 scenario) rainfall patterns and trend. Segele et al. (2009) found that after the effect of ENSO is removed, the Indian Ocean SSTs correlate only weakly with SREA.

Given the strength of observed ENSO teleconnections to SREA, we focus on the mechanisms of this teleconnection in this study. ENSO is a quasi-periodic oscillation that occurs as a result of air-ocean interactions in the tropical Pacific Ocean. Many studies have shown its connection to SREA as well as 
Blue Nile River flow, with the warm phase (El Niño) causing rainfall deficits and the cold phase (La Niña) causing rainfall excess (Tadesse 1994; Camberlin 1995; Seleshi and Demaree 1995; Segele and Lamb 2005; Block and Rajagopalan 2007). Relatively fewer studies have examined the processes that explain this ENSO teleconnection (Segele et al. 2009; Diro et al. 2011a; Gleixner et al. 2017). Proposed mechanisms include ENSO's influence on the Mascarene high, the position of the African easterly jet, westerlies from the Atlantic Ocean, the intensity of the southeasterly Somali jet, and, perhaps more notably (and more recently; Gleixner et al. 2017), upper-level circulation changes and the intensity of the tropical easterly jet (TEJ). Some of these easterly jets are also related to the South Asian monsoon system and experience a weakened intensity during El Niño events. The South Asian monsoon, in turn, is highly correlated with SREA (both decrease during an El Niño event) and likely shares some common mechanisms of variability (Berhane et al. 2014; Gleixner et al. 2017).

In this paper, we will focus on the role of the TEJ. The TEJ is an upper-level zonal jet over South Asia and Africa that occurs during summer months (usually June-September) due to the meridional temperature difference between the equatorial Indian Ocean and the Tibetan Plateau region in the upper troposphere (Koteswaram 1958). The north-south temperature gradient is related to TEJ intensity through the thermal wind relation (Abish et al. 2013). The jet attains maximum wind speed $\left(>30 \mathrm{~m} \mathrm{~s}^{-1}\right)$ at its core, west of southern India (Krishnamurti 1971), and contributes to about half of the total mass inflow over the Ethiopian highlands (Viste and Sorteberg 2013). It has been shown that the jet is maintained by the release of available potential energy from tropical divergent circulations (Chen 1980; Chen and van Loon 1987), and some previous studies have called it the upper limb of Hadley and Walker circulation (Abish et al. 2013; Nithya et al. 2017). The Tibetan anticyclone, important for jet generation, is known to be influenced primarily by plateau-induced heating, and orography plays a secondary role (Flohn 1964; Liu et al. 2007). Studies on the South Asian summer monsoon have recognized the profound effect of the jet, and its correct simulation is important for seasonal predictions and weather forecasting in that region (Rao and Srinivasan 2016). According to Webster and Fasullo (2002), the jet's impact on the South Asian monsoon is due to circulation induced by the ageostrophic meridional velocity at the jet entrance.

Studies in eastern Africa have shown significant links between the TEJ and summer rains. Hulme and Tosdevin (1989) and Camberlin (1995) discussed the strength and extent of the jet in relation to Sudanese and Ethiopian rainfall, respectively. Segele et al. (2009) showed that there are strong variations in jet strength between wet and dry events in the Horn of Africa, while the location of the jet shows little variation. Berhane et al. (2014) showed significant correlation between areaaveraged TEJ winds and SREA, with significance higher toward the end of the season. The region of the SREA maximum occurs near the jet exit region (where the zonal velocities decrease westward of the peak) and the deceleration of the jet is associated with an ageostrophic meridional circulation, similar in principle to the circulation found at the jet entrance for the South Asian monsoon (Flohn 1964; Grist and Nicholson 2001).
This suggests upper-level divergence over the area of the jet exit region that promotes convection by ascent due to lower-level convergence as a result of Dines compensation (Diro et al. 2011b; Hastenrath 1991; Grist and Nicholson 2001) and is the proposed mechanism of impact of the jet on the rainfall. Since the jet is sensitive to the large-scale tropical circulation, the interannual variations in this circulation due to ENSO can influence the jet characteristics (Chen and van Loon 1987). Diro et al. (2011a) and Gleixner et al. (2017) performed modeling experiments and demonstrated changes in the TEJ due to ENSO (e.g., decrease in zonal velocities during an $\mathrm{El} \mathrm{Niño).} \mathrm{A} \mathrm{recent} \mathrm{study} \mathrm{showed} \mathrm{im-}$ pacts from extratropical circulation in the Southern Hemisphere on the TEJ (Nicholson and Klotter 2020). Changes in meridional temperature gradient could also impact the jet, for example, through warming of the Indian Ocean during an El Niño event. Weakening of the Tibetan high during an El Niño, due to upperlevel Rossby waves (Goswami and Xavier 2005; Shaman and Tziperman 2005), could decrease the meridional gradient as well. These variations in the jet characteristics could then be conveyed to SREA through the proposed mechanism described above.

It can be argued that an accurate simulation of these physical processes is necessary for models to be reliable for future projections. Previous research has often focused on accurate reproduction of historical precipitation climatology (Otieno and Anyah 2013; Jury 2015; Li et al. 2016), which does not necessarily equate to an accurate representation of physical drivers of SREA. James et al. (2018) argued that region-specific, processoriented evaluation is fundamental for model development and application. This is particularly the case for regions with significant climate variability and uncertain projections. With this as motivation, we perform a process-based evaluation of GCMs to address the following questions:

1) Do GCMs accurately capture the statistical relationship between ENSO and SREA?

2) Is variation across the models' ENSO-SREA relationship mediated by TEJ coupling?

3) Do we see consistent evidence of the proposed TEJ-SREA coupling mechanism across models?

We answer these questions using a combination of observation, reanalysis, and model simulations. For models, we focus on the "historical" experiment simulations of CMIP5 GCMs and supplement the analysis with simulations forced with observed sea surface temperatures [Atmospheric Model Intercomparison Project (AMIP)] to evaluate the effect of improved SSTs on model simulation of ENSO teleconnections. We show that even when we limit our analysis in each model to areas of high SREA within each model, models differ in terms of their connection to ENSO. This is not primarily because models fail to capture ENSO influence on the TEJ. Rather it is because the TEJ-SREA connection is highly variable across models. Moreover, we demonstrate that it is not the TEJ over the Indian Ocean that has the strongest impact, but rather the averaged jet over Africa and the western Indian Ocean.

\section{Data and methods}

Precipitation fields were drawn from the CenTrends precipitation record, which offers gridded precipitation estimates 
TABLE 1. CMIP5 models used in this study.

\begin{tabular}{|c|c|c|c|c|}
\hline No. & Model name & Modeling center & Resolution & AMIP availability \\
\hline 1 & CanESM2 & $\begin{array}{l}\text { Canadian Centre for Climate Modeling } \\
\text { and Analysis, Canada }\end{array}$ & $1.875^{\circ} \times 1.875^{\circ}$ & \\
\hline 2 & CCSM4 & $\begin{array}{l}\text { National Center for Atmospheric } \\
\text { Research, United States }\end{array}$ & $1.25^{\circ} \times 0.94^{\circ}$ & Yes \\
\hline 3 & CESM & $\begin{array}{l}\text { National Center for Atmospheric } \\
\text { Research, United States }\end{array}$ & $1.25^{\circ} \times 0.94^{\circ}$ & Yes \\
\hline 4 & CMCC-CM & $\begin{array}{l}\text { Centro Euro-Mediterraneo per I } \\
\text { Cambiamenti Climatici, Italy }\end{array}$ & $0.75^{\circ} \times 0.75^{\circ}$ & Yes \\
\hline 5 & CNRM-CM5 & $\begin{array}{l}\text { Centre National de Recherches } \\
\text { Meteorologiques/Centre European de } \\
\text { Recherche et Formation Avancees en } \\
\text { Calcul Scientifique, France }\end{array}$ & $1.4^{\circ} \times 1.4^{\circ}$ & Yes \\
\hline 6 & GFDL CM3 & $\begin{array}{l}\text { NOAA, Geophysical Fluid Dynamics } \\
\text { Laboratory, United States }\end{array}$ & $2.5^{\circ} \times 2^{\circ}$ & Yes \\
\hline 7 & GFDL-ESM2M & $\begin{array}{l}\text { NOAA, Geophysical Fluid Dynamics } \\
\text { Laboratory, United States }\end{array}$ & $2.5^{\circ} \times 2^{\circ}$ & \\
\hline 8 & GFDL-ESM2G & $\begin{array}{l}\text { NOAA, Geophysical Fluid Dynamics } \\
\text { Laboratory, United States }\end{array}$ & $2.5^{\circ} \times 2^{\circ}$ & \\
\hline 9 & HadGEM2-CC & $\begin{array}{l}\text { Met Office Hadley Centre, United } \\
\text { Kingdom }\end{array}$ & $1.25^{\circ} \times 1.88^{\circ}$ & \\
\hline 10 & HadGEM2-ES & $\begin{array}{l}\text { Met Office Hadley Centre, United } \\
\text { Kingdom }\end{array}$ & $1.25^{\circ} \times 1.88^{\circ}$ & \\
\hline 11 & IPSL-CM5A-LR & Institut Pierre-Simon Laplace, France & $1.8^{\circ} \times 3.75^{\circ}$ & Yes \\
\hline 12 & IPSL-CM5B-LR & Institut Pierre-Simon Laplace, France & $1.8^{\circ} \times 3.75^{\circ}$ & Yes \\
\hline 13 & MIROC 5 & $\begin{array}{l}\text { Atmosphere and Ocean Research } \\
\text { Institute (The University of Tokyo), } \\
\text { National Institute for Environmental } \\
\text { Studies, and Japan Agency for Marine- } \\
\text { Earth Science and Technology, Japan }\end{array}$ & $1.4^{\circ} \times 1.4^{\circ}$ & Yes \\
\hline 14 & MRI-CGCM3 & Meteorological Research Institute, Japan & $1.1^{\circ} \times 1.1^{\circ}$ & Yes \\
\hline
\end{tabular}

for eastern Africa, at a resolution of $0.1^{\circ}$ from 1900 to 2014 . It is a "pooled" station dataset from different institutions that is extensively quality-controlled and has been shown to be more accurate than other available long-record gridded precipitation datasets (Funk et al. 2015). The Extended Reconstructed Sea Surface temperature version 3b (ERSSTv3b; Smith et al. 2008) monthly values are used for observed sea surface temperature (SST). Monthly zonal and meridional wind speeds, gridded at $2.5^{\circ}$ resolution and available from 1948 to the present, are from the National Centers for Environmental Prediction-National Center for Atmospheric Research (NCEP-NCAR) reanalysis. Monthly winds from the Modern-Era Retrospective Analysis for Research and Applications, version 2 (MERRA-2 at $50 \mathrm{~km} \times$ $50 \mathrm{~km}$ resolution; Gelaro et al. 2017) are used as additional reanalysis product, even though their time of availability (1980 onward) is shorter than NCEP-NCAR reanalysis.

We used climate model outputs from coupled GCMs participating in phase 5 of the Coupled Model Intercomparison Project (CMIP5) (Taylor et al. 2012). We chose 14 models (Table 1) based on previous studies. These are the models that simulated nonlinear ocean-atmosphere coupling as well as rainfall in the eastern Pacific correctly (Cai et al. 2014) and had shown some ability to capture observed teleconnections between large-scale drivers and SREA (Bhattacharjee and Zaitchik
2015; Siam and Eltahir 2017). For each model, we used the "historical" simulation, in which the models are forced with greenhouse gases and aerosol observed/estimated after the preindustrial period (1850-2005). To be consistent across the whole array of models, only the first ensemble member for each model is utilized. The monthly outputs used are SST, precipitation, and winds. Last, we also utilized the "AMIP simulations" (1981-2005), where the same atmospheric models are forced with observed SSTs rather than coupled to an ocean model.

We define SREA as the region of maximum summertime precipitation that is found within $7^{\circ}-14^{\circ} \mathrm{N}$ and $32^{\circ}-40^{\circ} \mathrm{E}$ (Fig. 1a). We assume homogeneity in ENSO teleconnections in this region but note that researchers in the past have attempted to divide this region into clusters and subregions to show how drivers may vary across space (Gissila et al. 2004; Diro et al. 2011a). All of the monthly datasets are averaged over the July-September (JAS) season to get seasonal averages. June is not included because it is considered to be a transition month (Nicholson 2014) and was shown to have extremely weak ENSO-related impact on precipitation by Berhane et al. (2014, their Fig. 3). The period of analysis of our study is 1950-2005, based on reanalysis and model data availability.

Because of spatial biases in the models, an "SREA box" is defined separately for each model, based on two criteria that 
TABLE 2. ENSO years from 1950 to 2005 in observations.

\begin{tabular}{ll}
\hline \hline El Niño & $1957,1965,1972,1982,1987,1997,2002$ \\
La Niña & $1970,1973,1975,1988,1998,1999$ \\
\hline
\end{tabular}

represent climatological rainfall characteristics: 1) more than half of annual rainfall ( $>50 \%$ ) occurs in JAS season (the exact value of this threshold was adjusted slightly based on the model, and, for IPSL models, none of the possible regions satisfied this so the threshold was decreased to $35 \%$ ) and 2) JAS rainfall is high (i.e., $>400 \mathrm{~mm}$ ). This value is somewhat subjective and had to be decreased to $200 \mathrm{~mm}$ for IPSL-CM5BLR, which has a substantial dry bias. Grid point selection is not as sensitive to this threshold once the first criterion is applied. The area obtained from these criteria is the SREA box for a given model or observational dataset (Fig. 1; exact thresholds and coordinates are listed in Table S1 in the online supplemental material). It is noted that defining the maximum summertime precipitation region in each model using these criteria brought model results closer to observations in all cases, relative to analyses performed using a fixed geography. This includes analysis of the ENSO teleconnection, jet associations, and also subseasonal correlations between ENSO and SREA (not shown). For this study ENSO conditions are defined using the average JAS Niño-3.4 index, which is the SST in the eastcentral tropical Pacific over $5^{\circ} \mathrm{S}-5^{\circ} \mathrm{N}, 120^{\circ}-170^{\circ} \mathrm{W}$ (Trenberth 1997). ENSO anomalies tend to peak in winter, and summer Niño-3.4 values correlate strongly with values in the following winter (Walker et al. 2015).

Time series of variables for JAS season were first detrended by estimating and removing a least squares linear trend for all grid points, and then correlations (at zero lag) were computed (see Fig. S1 for details). Statistical significance of the correlation coefficient is computed by the Student's $t$ test, and significance at the $10 \%$ level is highlighted. Additionally, we analyze composites. A composite of a given category is calculated by averaging a variable (e.g., JAS rainfall for eastern Africa) for all the years that fall in that category. An El Niño rainfall composite is then the average of JAS rainfall for all El Niño years. Similarly, a La Niña rainfall composite is the average of JAS rainfall for all La Niña years. While ENSOs can range from weak to strong, we chose only strong El Niño and La Niña years for our composites, defined by the years when the JAS Niño-3.4 index exceeds 1 standard deviation. Table 2 provides a list of these years for observations. Last, we computed the difference of the El Niño and the La Niña composite, which we call an ENSO composite. All anomalies are calculated relative to a 1950-90 climatology.

\section{Results and discussion}

\section{a. Rainfall in eastern Africa}

Figure 1 shows the climatological JAS total precipitation (1950-90) for eastern Africa. The broad spatial patterns are quite similar across models, but there are differences in the intensity and location of the precipitation maximum. Spatial differences in models include smaller/shrunken size of high rainfall area (CMCC-CM, CNRM-CM5, GFDL CM3, GFDLESM2M, GFDL-ESM2G, IPSL-CM5A-LR, IPSL-CM5B-LR, MRI-CGCM3) or two distinct locations of peak rainfall (CanESM2, CCSM4, CESM, HadGEM2-CC, HadGEM2-ES, MIROC5). These spatial differences are generally captured by model-specific boxes, except in cases where the area of highest summertime rainfall does not coincide with the area of summertime precipitation dominance-that is, the two thresholds we applied do not combine to include the area with the most rainfall. Examples of these models are CCSM4 and CESM, which split the SREA region into two areas around the absolute precipitation maximum, and CanESM2 and MIROC5, which have precipitation maxima that spill beyond the boundaries set by the box. Even for these models, however, the model-specific boxes capture areas within the high summer precipitation zone.

Discrepancies in the simulation of total seasonal rainfall magnitude are not a primary concern for predicting interannual precipitation variability, as they can be corrected using techniques like bias correction and variance scaling. Some models clearly have a high bias (e.g., MIROC5, CNRM-CM5, CanESM2) and some a low bias (e.g., IPSL-CM5B-LR, GFDL CM3, CCSM4, CESM) - but it is in fact possible to have this magnitude of difference due to parameterizations, even in models that capture regional climate dynamics in a realistic way. Conversely, models with correct statistics can be right for the wrong reasons due to compensating errors. In fact, Bhattacharjee and Zaitchik (2015) noted specifically for the Nile headwaters that models that ranked best according to precipitation statistics failed to capture teleconnections from global SSTs and other large-scale climate modes. This provides motivation for exploring model differences that arise from drivers of large-scale variability.

\section{b. ENSO teleconnections to eastern Africa}

Next, we examine model representation of ENSO-associated precipitation variability. Negative anomalies in ENSO composites (Fig. 2) made by differencing El Niño and La Niña composites show dry conditions in El Niño relative to La Niña, and positive anomalies show dry La Niña relative to El Niño. When we focus on the model-specific region of interest, we notice that the precipitation variability due to ENSO is diverse across models. Qualitatively speaking, some models (CCSM4, GFDL CM3, GFDL-ESM2G) have areas of positive El Niñorainfall relationship mixed with areas of negative El Niñorainfall relationship. This is in contrast to observations and the other models included in this study, which show consistent negative relationships between $\mathrm{El}$ Niño and summer rains. There is also some variation in simulated magnitude of the ENSO impact on rainfall, even among models that agree on the sign of the relationship. A caveat here is that the strength of association in these composites is sensitive to the magnitude of variability in the central-eastern Pacific that exists within a given model, since these composites are made by ENSO events defined by standard deviation in a particular model (note that Fig. S2 shows variability and standard deviation of Niño-3.4 for observations and models).

For a quantification of these ENSO teleconnections to precipitation, we do a linear correlation of Niño-3.4 as a point time series with the gridded precipitation time series. The correlation 


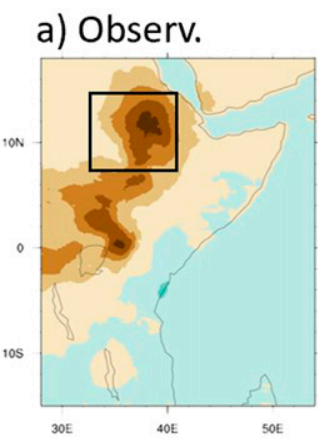

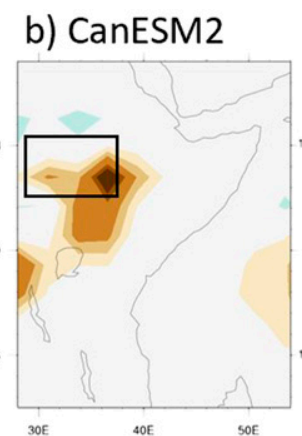

c) $\mathrm{CCSM} 4$

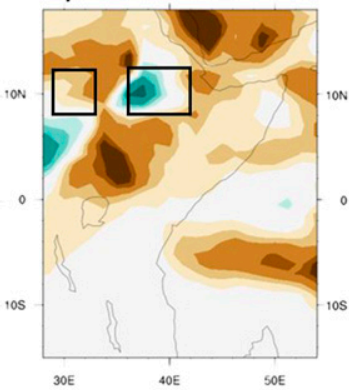

g) GFDL-CM3

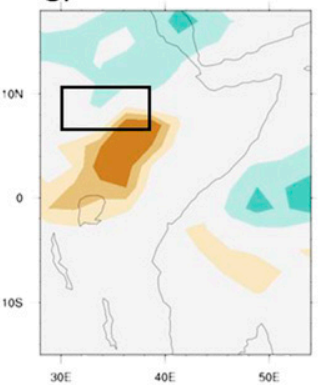

I) IPSL-CM5A-LR h) GFDL-ESM2M

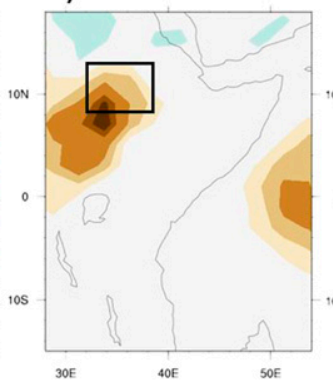

m) IPSL-CM5B-LR d) CESM
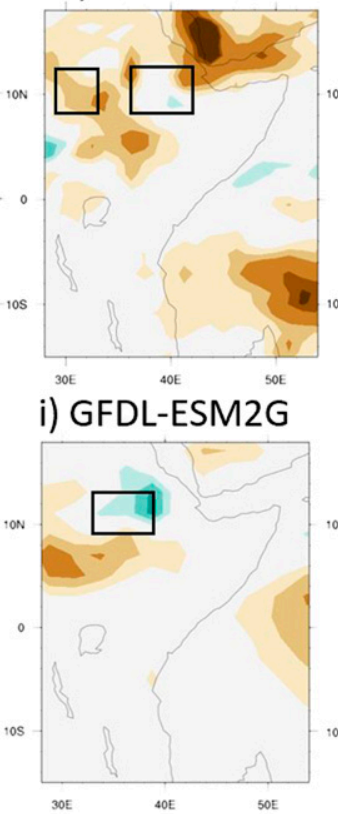

n) MIROC5
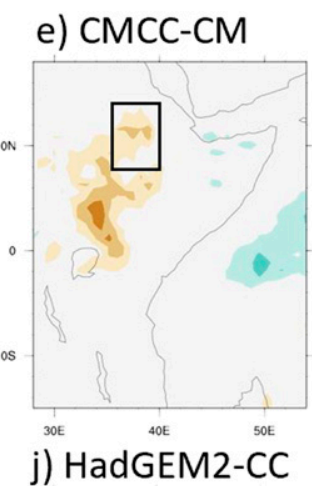

k) HadGEM2-ES
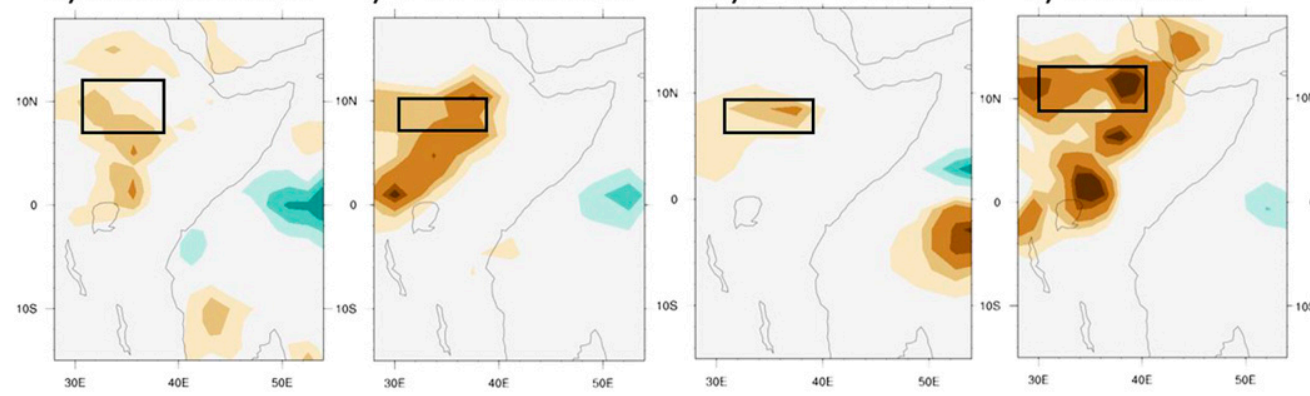

o) MRI-CGCM3
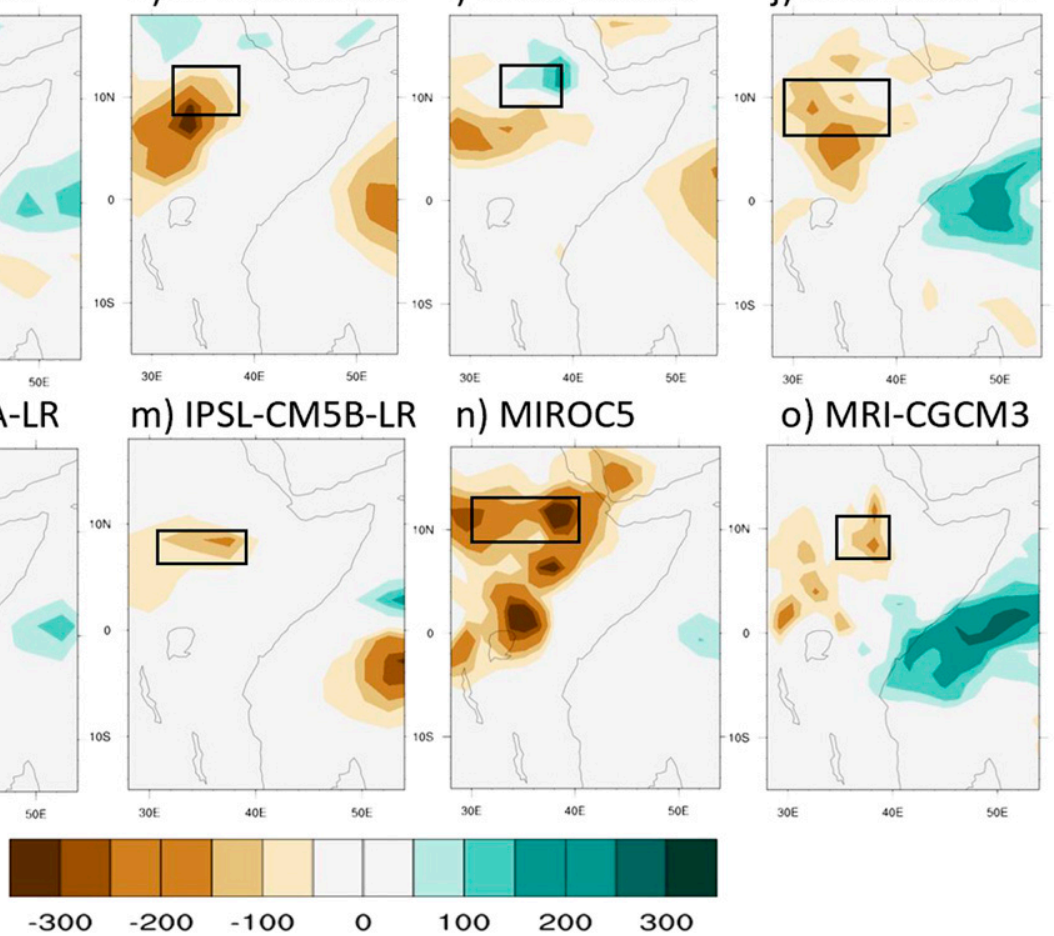

FIG. 2. JAS ENSO composites for eastern Africa, made by differencing El Niño and La Niña composites [mm yr ${ }^{-1}$; same as units for El Niño (or La Niña) composite where seasonal rainfall is averaged for all El Niño (or La Niña) years in Table 2]. Negative values show dry El Niño relative to La Niña, and positive values show dry La Niña relative to El Niño.

coefficients are shown in Fig. 3, with significant values at $95 \%$ highlighted. Essential characteristics of Fig. 3 match with the ENSO composites. A negative correlation for most of the area above the equator shows that an increase in tropical centraleastern Pacific SST leads to decrease in rainfall; positive values to the south and near the coast indicate an increase in rainfall. In no model does the spatial pattern of correlations over the Horn of Africa completely match observations, although HadGEM2-CC, HadGEM2-ES, MIROC5, GFDL-ESM2M, and MRI-CGCM3 come quite close. IPSL-CM5A-LR is similar to observations, except for the wrong sign below the equator and for coastal regions. CNRM-CM5, CMCC, and IPSL-CM5B-LR's area of negative correlations is smaller in size and mostly limited to the SREA region. CCSM4 and CESM are quite similar to observed except that some areas in the SREA region have the wrong sign. The observed correlation coefficient averaged over the entire region is -0.69 . All models get a correct sign for this average value, but the values range from -0.02 to -0.68 (Table 3). The lowest (insignificant) correlations are seen in CCSM4, GFDL CM3, and GFDL-ESM2G. The rest of the models have significant correlations, but only three models, namely MIROC5, IPSL-CM5A-LR, and CNRM-CM5, have a value that is statistically similar to observed (at $90 \%$ significance; two-sided Student's $t$ test). The question we explore is: What causes these differences among the models?

\section{c. Associations with the tropical easterly jet}

According to reanalysis, the TEJ $(150 \mathrm{hPa})$ has a wind speed maximum of over $30 \mathrm{~m} \mathrm{~s}^{-1}$ during the summer, located slightly to the west of the tip of India (Fig. 4a; MERRA-2 is similar to NCEP-NCAR and shown in Fig. S3). The jet is associated with the geopotential height gradient between the Indian Ocean and 
a) Observ.

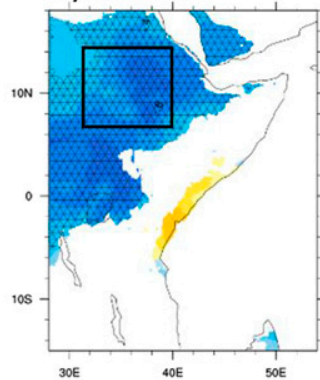

f) CNRM-CM5

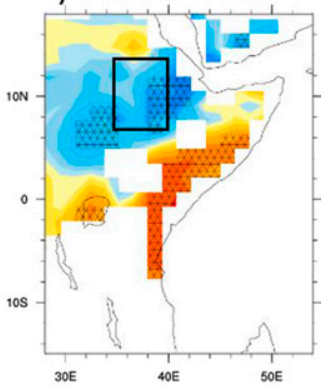

k) HadGEM2-ES

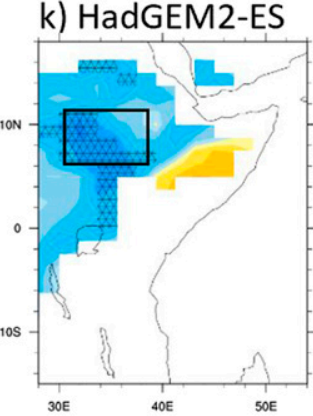

b) CanESM2

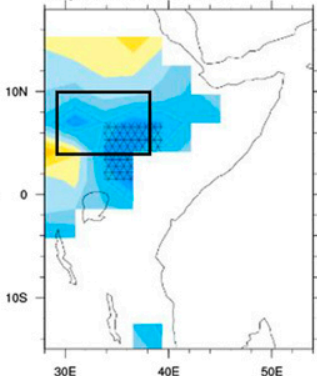

g) GFDL-CM3

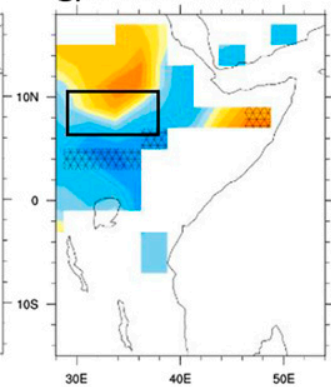

I) IPSL-CM5A-LR c) $\mathrm{CCSM} 4$

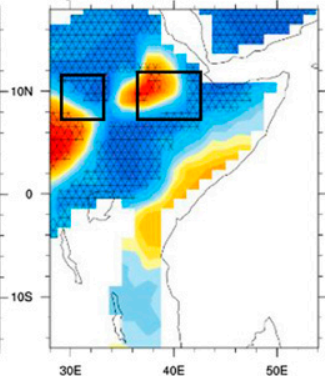

h) GFDL-ESM2M d) CESM

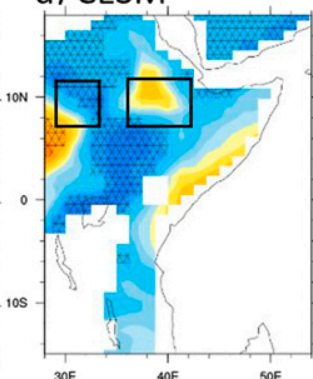

i) GFDL-ESM $2 G$

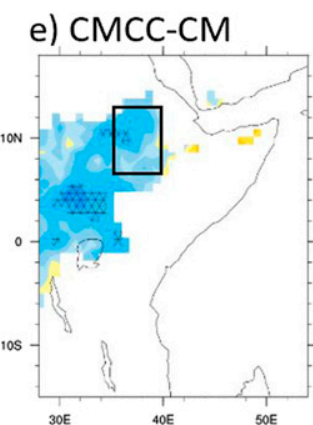

j) HadGEM2-CC
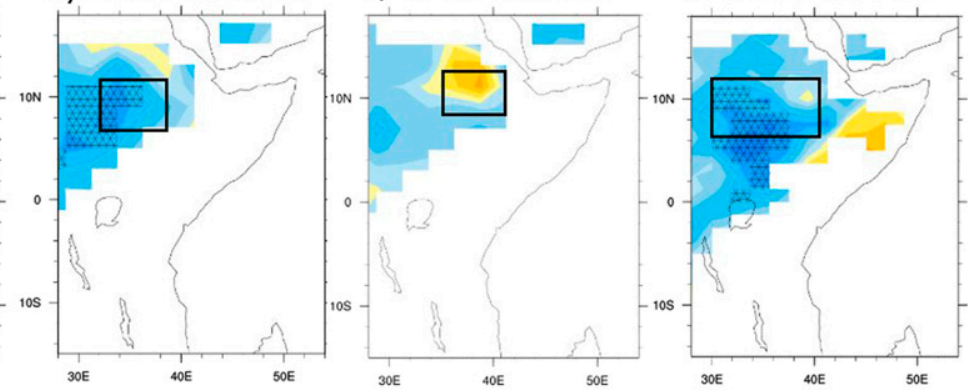

m) IPSL-CM5B-LR

n) MIROC5
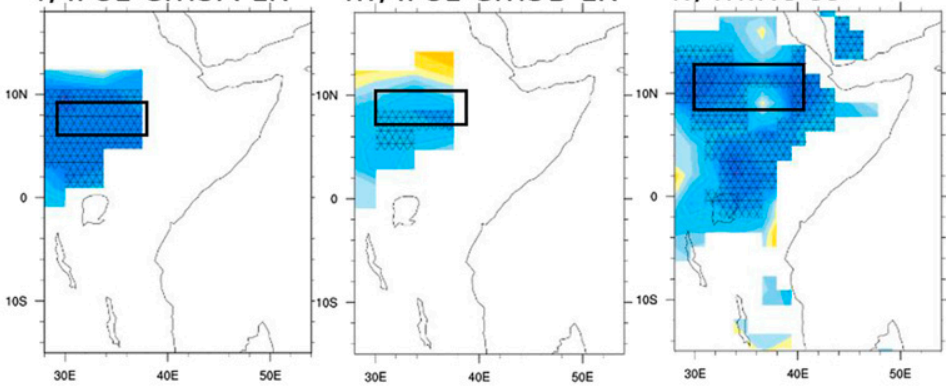

o) MRI-CGCM3
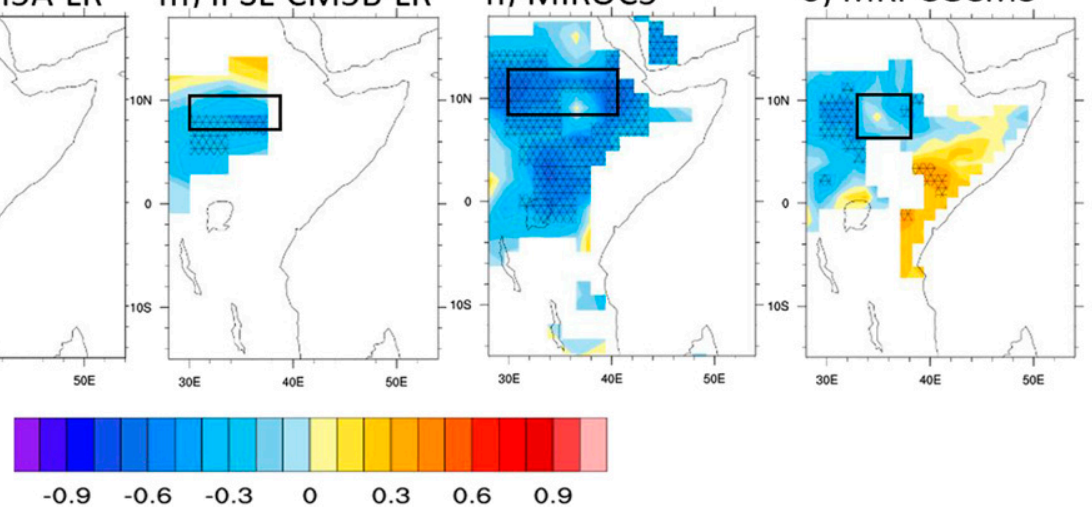

FIG. 3. Correlation of precipitation with Niño-3.4; hatching shows statistically significant linear correlation (Student's $t$ test, two-sided, $90 \%$ ). Boxes are the defined "SREA" region, according to criteria discussed in the text. Shown only for areas with JAS seasonal precipitation higher than $50 \mathrm{~mm}$.

Tibet and Southwest Asia (Fig. 4b). The jet maximum roughly corresponds to the longitude where the upper-level large-scale velocity potential changes from divergent to convergent (Fig. 4c). While the peak velocities occur in the "jet core" region over the Indian Ocean, the jet is discernable as a velocity maximum all the way to the West African coast. The TEJ is clearly evident in a cross section of winds at $35^{\circ} \mathrm{E}$, over the SREA region (Fig. $4 \mathrm{~d}$ ).

The jet in models is qualitatively similar to reanalysis (Fig. S3), with the mean values (averaged over $5^{\circ}-15^{\circ} \mathrm{N}$ ) slightly lower than reanalysis (Fig. 4e). More importantly, the longitude of peak jet velocities varies across models: CanESM2, CCSM4, CESM, and all GFDL models place the core farther west than observed, while IPSL models and MRI-CGCM3 place the core farther east than observed.

ENSO-induced changes in the TEJ can be understood as part of a pan-tropical pattern of change in upper-level winds. The jet in turn is believed to influence SREA through varying jet speed structure over Africa that may change the upper-level divergence (Fig. 4d). These ENSO-jet and jet-precipitation associations can be quantified using correlations. Figure 5 shows correlation between Niño-3.4 as a point time series and easterly wind speeds (easterlies are signed positive to focus on the magnitude of the jet). Negative correlation means an increase in Niño-3.4 SSTs decreases the zonal jet winds. A few models (CanESM2, CCSM4, CESM) stand out with a slight westward shift of correlation structure, likely representing the westward shift of Walker cell compared to reanalysis (positive values over Bay of Bengal and west India). These are the same models that have a westward bias of TEJ in the climatology, and this shift is also evident in velocity potential climatology (not shown). IPSL-CM5B-LR and MRI-CGCM3's slight eastward bias in climatology also has a footprint in the correlation structure: negative values extend all the way east to the Maritime Continent, as opposed to models with a westward bias that show 
TABLE 3. Table of two-way correlations for Niño-3.4, SREA, and TEJ: all significant correlations are in bold, and correlations no different from observed (at the $90 \%$ significance level, two-sided) are in italics.

\begin{tabular}{lccc}
\hline \multicolumn{1}{c}{ Name } & Niño-3.4-SREA (I) & Niño-3.4-TEJ index (II) & SREA-TEJ index (III) \\
\hline Observations/reanalysis & $\mathbf{- 0 . 6 9}$ & $\mathbf{- 0 . 5 3}$ & $\mathbf{0 . 6 9}$ \\
CanESM2 & $-\mathbf{0 . 3 2}$ & $\mathbf{- 0 . 5 2}$ & $\mathbf{0 . 3 4}$ \\
CCSM4 & -0.06 & $\mathbf{- 0 . 6 9}$ & 0.13 \\
CESM & $-\mathbf{0 . 2 8}$ & $\mathbf{- 0 . 5 1}$ & 0.23 \\
CMCC-CM & $\mathbf{- 0 . 2 5}$ & $\mathbf{- 0 . 4 3}$ & $\mathbf{0 . 5 1}$ \\
CNRM-CM5 & $-\mathbf{0 . 4 9}$ & $\mathbf{- 0 . 6 5}$ & $\mathbf{0 . 5 5}$ \\
GFDL CM3 & -0.15 & $\mathbf{- 0 . 6 8}$ & 0.18 \\
GFDL-ESM2M & $-\mathbf{0 . 4 4}$ & $\mathbf{- 0 . 7 9}$ & $\mathbf{0 . 4 8}$ \\
GFDL-ESM2G & -0.02 & $\mathbf{- 0 . 6 6}$ & 0.10 \\
HadGEM2-CC & $\mathbf{- 0 . 4 3}$ & $\mathbf{- 0 . 5 1}$ & $\mathbf{0 . 6 3}$ \\
HadGEM2-ES & $\mathbf{- 0 . 4 8}$ & $\mathbf{- 0 . 5 2}$ & $\mathbf{0 . 4 6}$ \\
IPSL-CM5A-LR & $\mathbf{- 0 . 5 4}$ & $\mathbf{- 0 . 6 3}$ & $\mathbf{0 . 5 6}$ \\
IPSL-CM5B-LR & $\mathbf{- 0 . 4 2}$ & $\mathbf{- 0 . 5 6}$ & $\mathbf{0 . 5 1}$ \\
MIROC 5 & $\mathbf{- 0 . 6 8}$ & $\mathbf{- 0 . 7 8}$ & $\mathbf{0 . 6 2}$ \\
MRI-CGCM3 & $\mathbf{- 0 . 4 0}$ & $\mathbf{- 0 . 5 9}$ & $\mathbf{0 . 5 1}$ \\
\hline
\end{tabular}

negative values only until the Arabian Sea or west of India. Overall, for the TEJ region, most models have statistically significant correlations qualitatively similar to Fig. 5a.

Similarly, Fig. 6 shows the correlation between SREA as a point time series with easterly TEJ wind speed magnitudes. A positive correlation with precipitation means decrease in winds decreases precipitation. The strengths of precipitation-TEJ correlations are visibly low and different across the models, especially over the TEJ region (Fig. 6). The area of overlap for significant correlation of Niño-3.4 and precipitation over the TEJ region is noticeable (Figs. 5a and 6a). Models with westward (eastward) shift of Niño-3.4 correlations also show a westward (eastward) shift of SREA correlation [seen as positive values shifted westward (eastward) of the Arabian Sea (Bay of Bengal)].

These patterns can be distilled in plots of correlation as a function of longitude, averaged over the latitudes of maximum jet activity (Fig. 7). In observations, there is a clear negative association between the ENSO index and strength of the jet (Fig. 7a). This ENSO-TEJ coupling is significant west of $75^{\circ}-80^{\circ} \mathrm{E}$, with a maximum value of -0.6 at about $60^{\circ}-65^{\circ} \mathrm{E}$, which is a few degrees west of longitude of peak winds $\left(70^{\circ} \mathrm{E}\right.$; see Fig. 4). The correlation slowly becomes smaller westward of $65^{\circ} \mathrm{E}$, reaching a value of -0.5 at $30^{\circ} \mathrm{E},-0.4$ at $20^{\circ} \mathrm{E}$ and -0.35 at $5^{\circ} \mathrm{E}$. Most models have a peak correlation around $55^{\circ}-65^{\circ} \mathrm{E}$, but the westward decrease in correlations in models is generally similar to observations. Correlations between jet wind speed and SREA (Fig. 7b) are positive and of similar magnitude from $70^{\circ}$ to $0^{\circ} \mathrm{E}$ in observations, except that the values remain more or less the same all the way to the western African coast. When the same analysis is applied to models, there is a split between two populations of models: nine models show longitudinal patterns that are generally similar to observations, while five show substantially lower correlations, particularly east of $45^{\circ} \mathrm{E}$. Interestingly, these five models are five of the six that show weakest teleconnection between ENSO and SREA. These six models are shown in dotted lines in Figs. 7a and 7b-CanESM2, CCSM4, CESM, CMCC-CM, GFDL CM3, and GFDL-ESM2G. The GFDL models agree reasonably well with observations on the structure and strength of ENSO-TEJ correlations, but they fail to capture associations between TEJ and SREA. CMCC-CM is the opposite, as it has relatively week ENSO-TEJ correlation but is somewhat in agreement with observations on the TEJ to SREA correlation. The remaining models that are represented by dashed lines in Fig. 7 are notable in that their ENSO-TEJ correlation pattern is shifted west relative to observations and other models, as are their TEJ to SREA correlation patterns.

These discrepancies between models suggest that different models capture different aspects of the ENSO to SREA teleconnection. We define the TEJ index as the wind magnitude averaged for $5^{\circ}-65^{\circ} \mathrm{E}$ and $5^{\circ}-15^{\circ} \mathrm{N}$, which is the region of maximum variance and has been used in previous studies (Huang et al. 2019). We see that all models have significant ENSO-TEJ index correlations, and that for most models the value is statistically no different than observed (Fig. 8a, Table 3). If we look at the average correlations across models (Fig. 8a) we see much larger relative differences in the apparent coupling between the TEJ and precipitation (orange bars) than in the coupling between TEJ and ENSO (blue bars).

We now turn to the question of which of the connections we have examined explains the cross-model variability in ENSO teleconnections to SREA. As shown in Fig. 8b, intermodel variation in TEJ-precipitation coupling explains about $79 \%$ of the variability in ENSO teleconnection across models (Fig. 8b). Some but not all of this variability is due to differences in spatial structure seen in Fig. 4. Variability of the longitude where peak velocities of the jet are found explains $32 \%$ of the variability in ENSO teleconnection across models, which strongly suggests that the zonal location of the simulated jet is critical. By contrast, variability in the magnitude of wind velocity at the peak (also shown in Fig. 4) explains only $1 \%$ of the variability. Intermodel variations in ENSO-TEJ coupling also play a minor role, explaining less than $2 \%$ of the intermodel variation in ENSO-SREA teleconnections.

A number of questions arise from this analysis:

- Given the dependence on longitude, how much of the cross-model variance is due to SST biases that, among other factors, can cause tropical jets to have the wrong strength/location? (That this could 
a) $150 \mathrm{mb}$

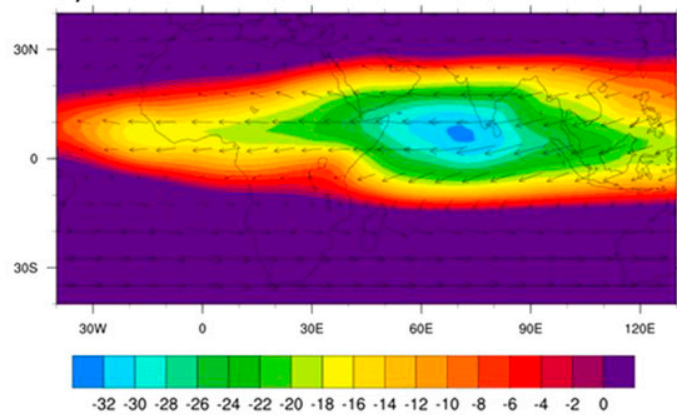

c) $150 \mathrm{mb}$ velocity potential

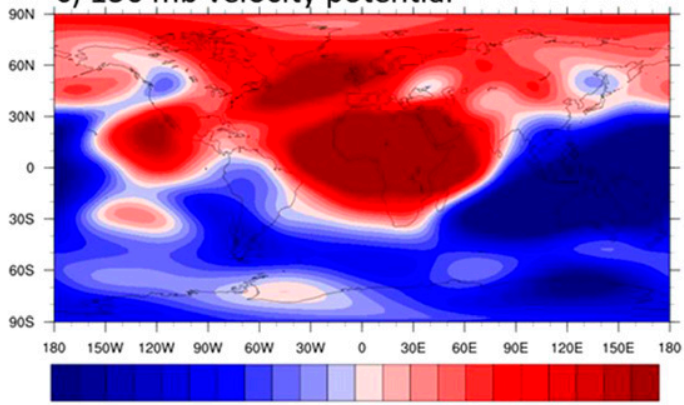

$\begin{array}{lllllllllllllllllllll}-10 & -9 & -8 & -7 & -6 & -5 & -4 & -3 & -2 & -1 & 0 & 1 & 2 & 3 & 4 & 5 & 6 & 7 & 8 & 9 & 10\end{array}$ e) TEJ zonal wind speed b) $150 \mathrm{mb}$

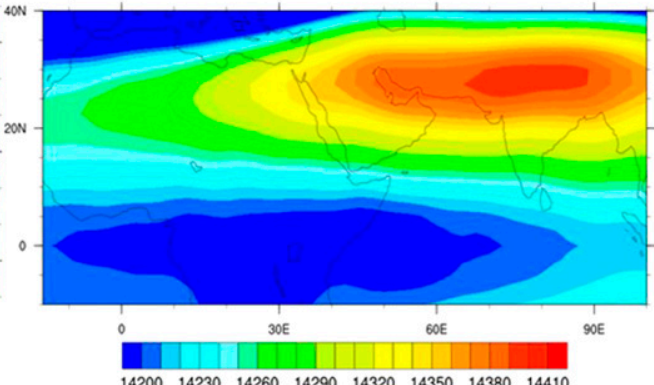

d) Winds at $35 \mathrm{E}$

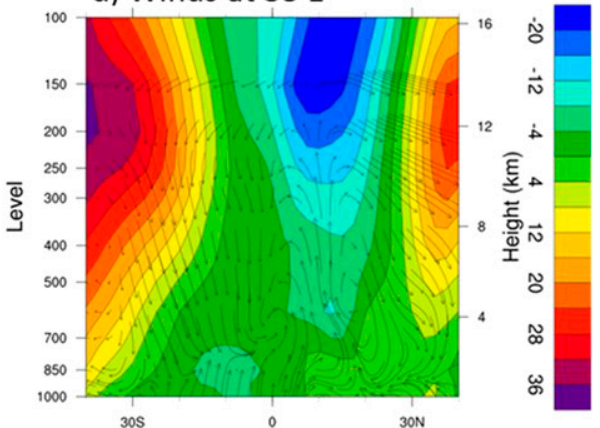

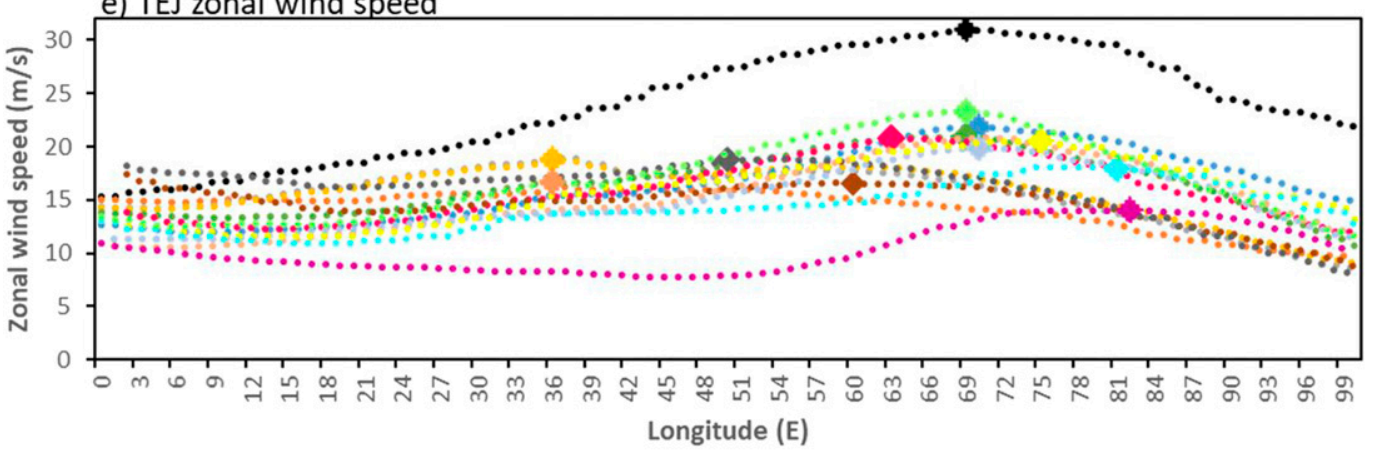

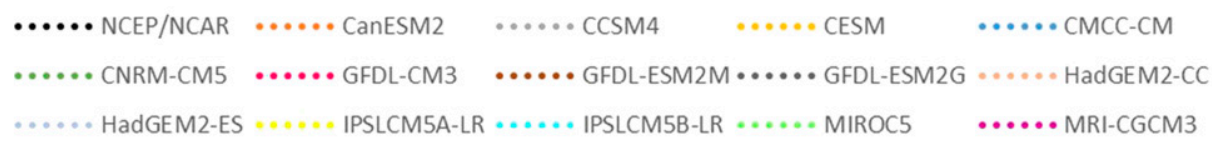

FIG. 4. (a) TEJ wind speeds climatology at $150 \mathrm{mb}\left(\mathrm{m} \mathrm{s}^{-1}\right)$; colors show zonal wind speed in the easterly direction. (b) Geopotential height at $150 \mathrm{mb}$. (c) Velocity potential at $150 \mathrm{mb}\left(10^{6} \mathrm{~m}^{2} \mathrm{~s}^{-1}\right)$. (d) Meridional cross section showing vertical and meridional winds in arrows; colors show zonal wind speed at the center of SREA $\left(35^{\circ} \mathrm{E}\right)$. (e) $150-\mathrm{mb}$ zonal wind speed, averaged over $5^{\circ}-15^{\circ} \mathrm{N}\left(\mathrm{m} \mathrm{s}^{-1}\right)$.

be a possibility is suggested by the differences between GFDL ESM2M and ESM2G, which have identical atmospheres).

- How much of the cross-model variance is due to incorrect simulation of the spatial structure of SST variability?

- How much of the cross-model variation is due to the atmospheric models incorrectly translating changes in SSTs associated with ENSO to the TEJ?

For example, it is possible that biases in the ocean simulation lead some CMIP5 GCMs to have a spatially shifted ENSO signal. This in turn could produce a shifted or otherwise altered
ENSO-TEJ correlation, and therefore an unrealistic representation of TEJ-mediated teleconnections to eastern Africa. Alternatively, it is possible that the modeled ENSO is in the right place and has the right magnitude, but that the atmospheric model fails to connect this SST variability to the TEJ or fails to connect the TEJ variability to summer rainfall of eastern Africa.

Additionally, the connection between the TEJ and SREA documented so far in this paper is descriptive rather than mechanistic. This raises the following questions: 
a) Observ.
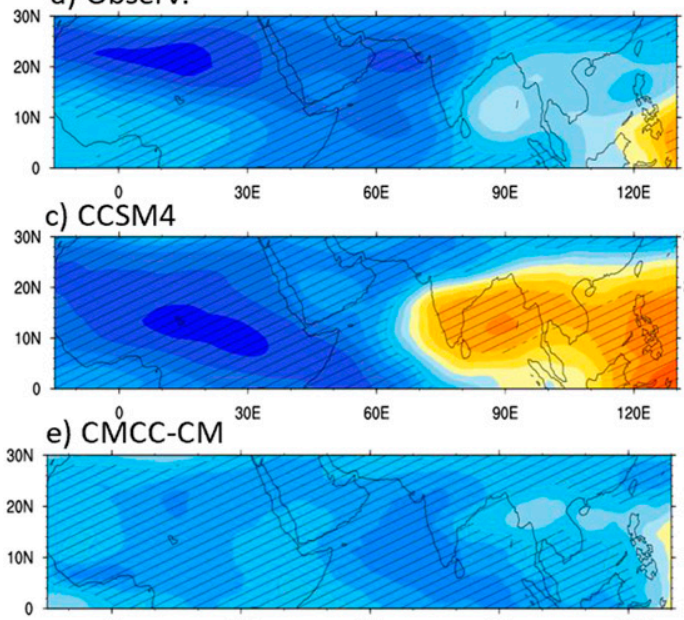

b) CanESM2

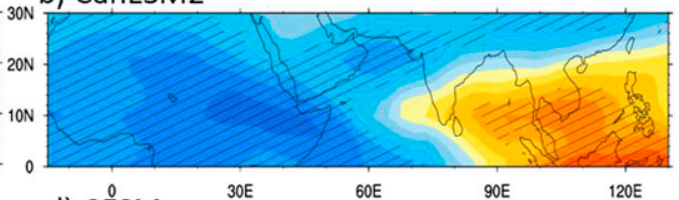

d) CE̊SM
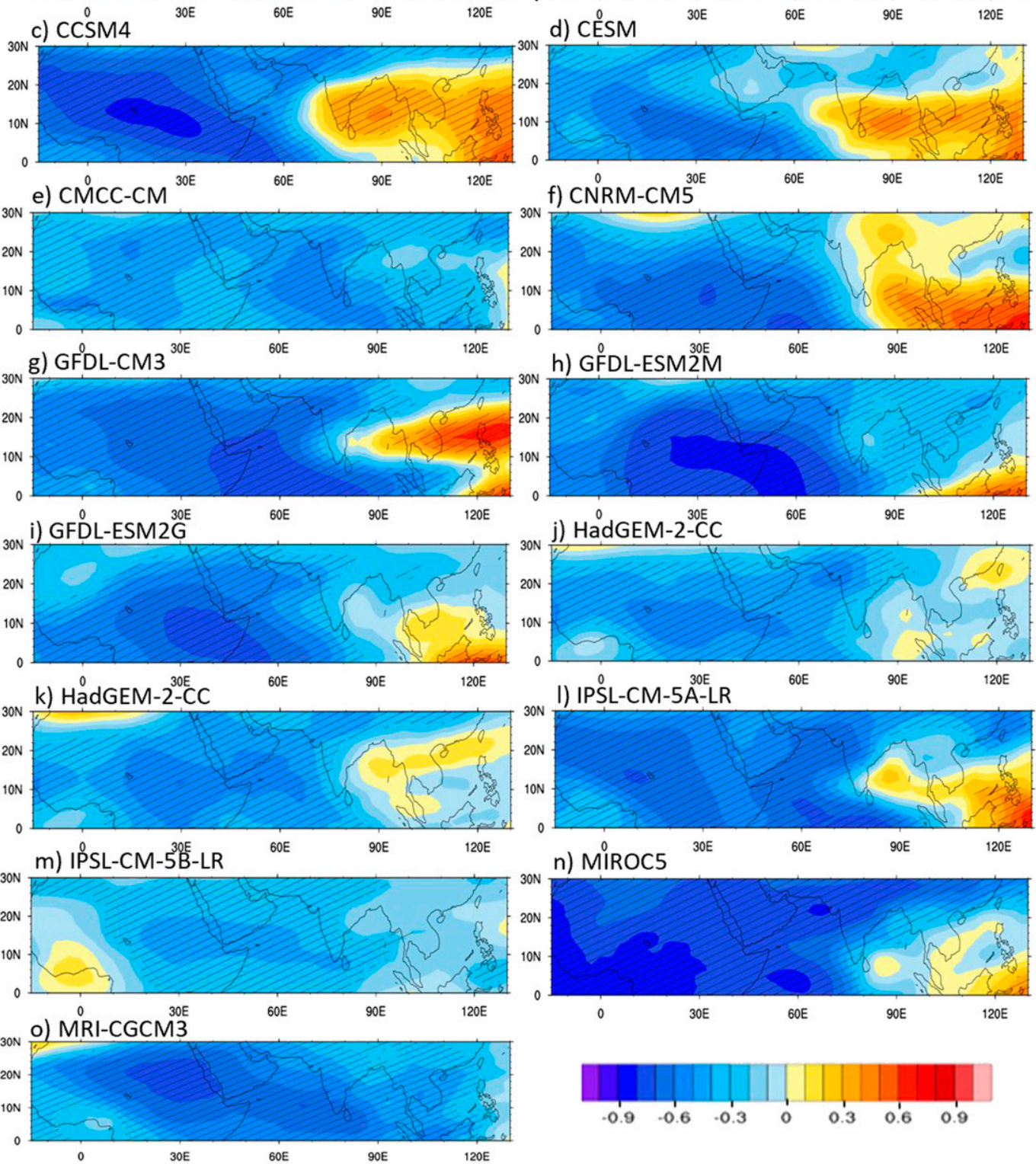

FIG. 5. Linear correlation between Niño-3.4 point time series and zonal wind magnitudes at TEJ level (easterlies are made positive for ease of representation). Hatching indicates $95 \%$ statistically significant correlation.

- Which locations within the TEJ are most important for explaining intermodel variance?

- Given that tropical jets feel the mean gradients in the tropics, is the TEJ-precipitation linkage also seen with other jets (Somali, AEJ) that should experience such connections?

\section{d. AMIP simulations}

One way of addressing the first set of questions above is through AMIP simulations in which the atmospheric model is run without ocean coupling, and SSTs are drawn from observations. Any biases that emerge from such simulations can be attributed to biases in the atmospheric model. Nine out of 14 models used in fully coupled models have AMIP simulations available in the archive. We note that these models only have output from 1980-2005, a shorter time period than is available for the coupled models.

For most models, ENSO-precipitation teleconnections across northeastern Africa were stronger in the AMIP simulations than 
a) Observ.
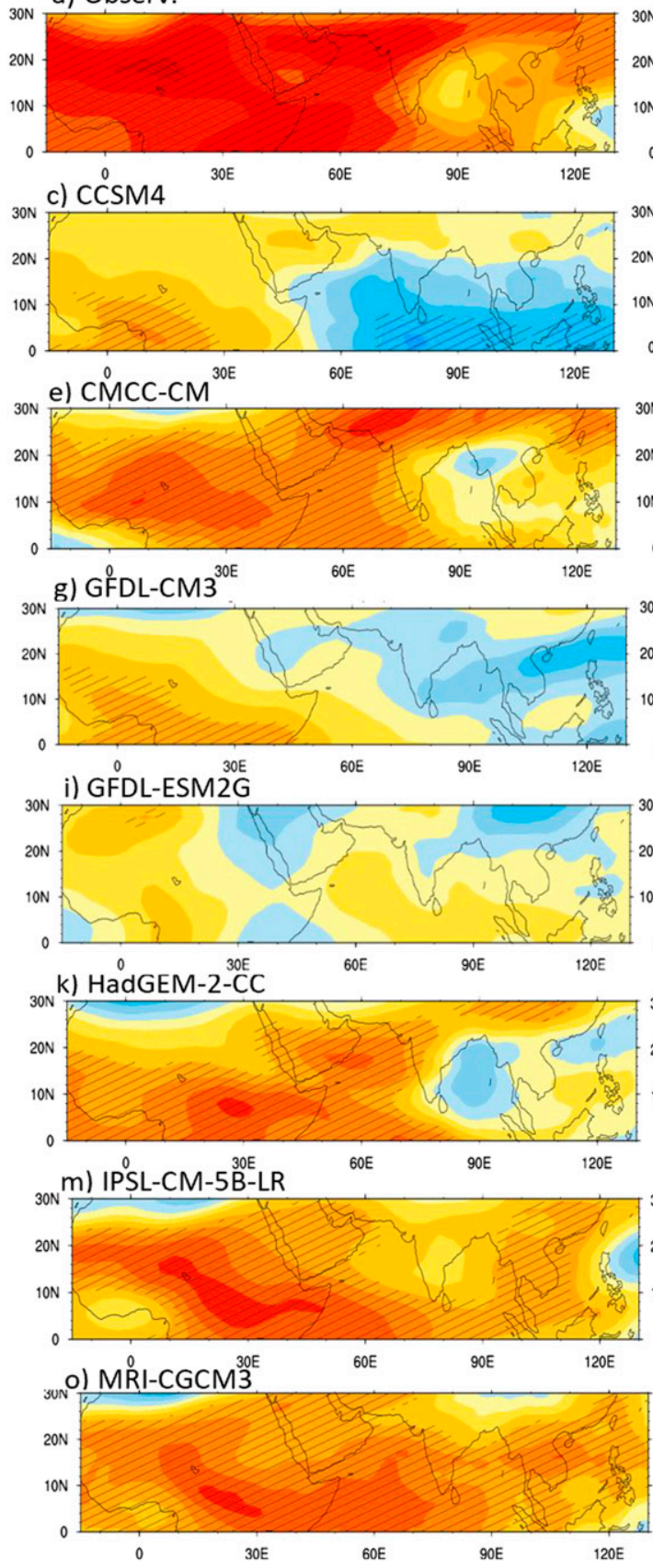

b) CanESM2
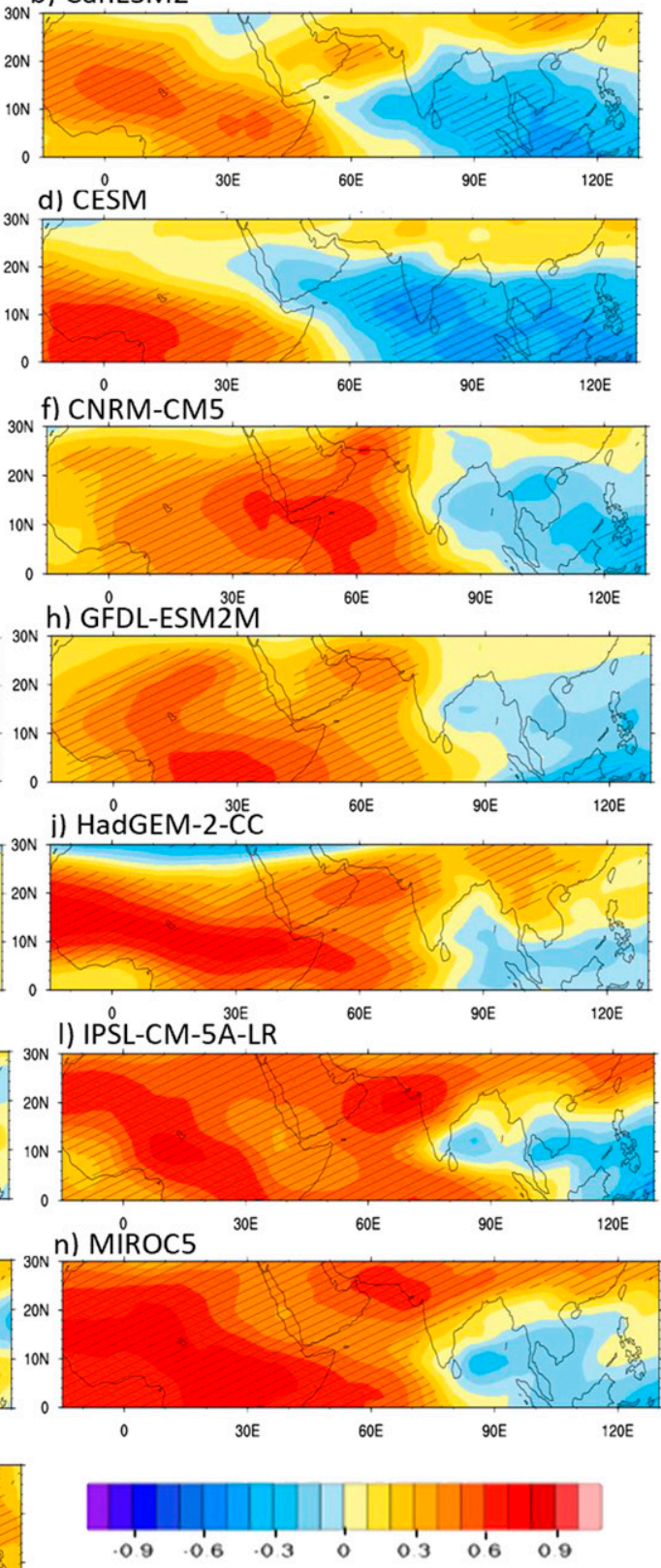

FIG. 6. Linear correlation between SREA as point time series and zonal wind magnitude at TEJ level (easterlies are made positive for ease of interpretation). Hatching indicates $95 \%$ statistically significant correlation.

they were for coupled simulations (Fig. 9, Table 4). Agreement with observed ENSO-SREA statistical relationship improved for most models (Table 4), with the exception of CCSM4, IPSLCM5A-LR (which did not increase), and MIROC5 (which decreased substantially). Note that the AMIP correlations cannot be compared directly to CMIP without taking into account the change in number of years; each set of simulations should be compared to the observed/reanalysis correlations for the period under consideration.
As with the coupled models there is again a high variation in TEJ-precipitation coupling (Fig. 10a). Six of the nine models have TEJ-precipitation associations that are statistically indistinguishable from observed, but MIROC5, CESM, and CCSM4 have significantly weaker correlations (Fig. 10). Compared with the coupled models, however, there is also more intermodel variation in ENSO-TEJ coupling.

Accounting for intermodel variability in ENSO teleconnections is more complicated in the AMIP relative to the CMIP simulations. 

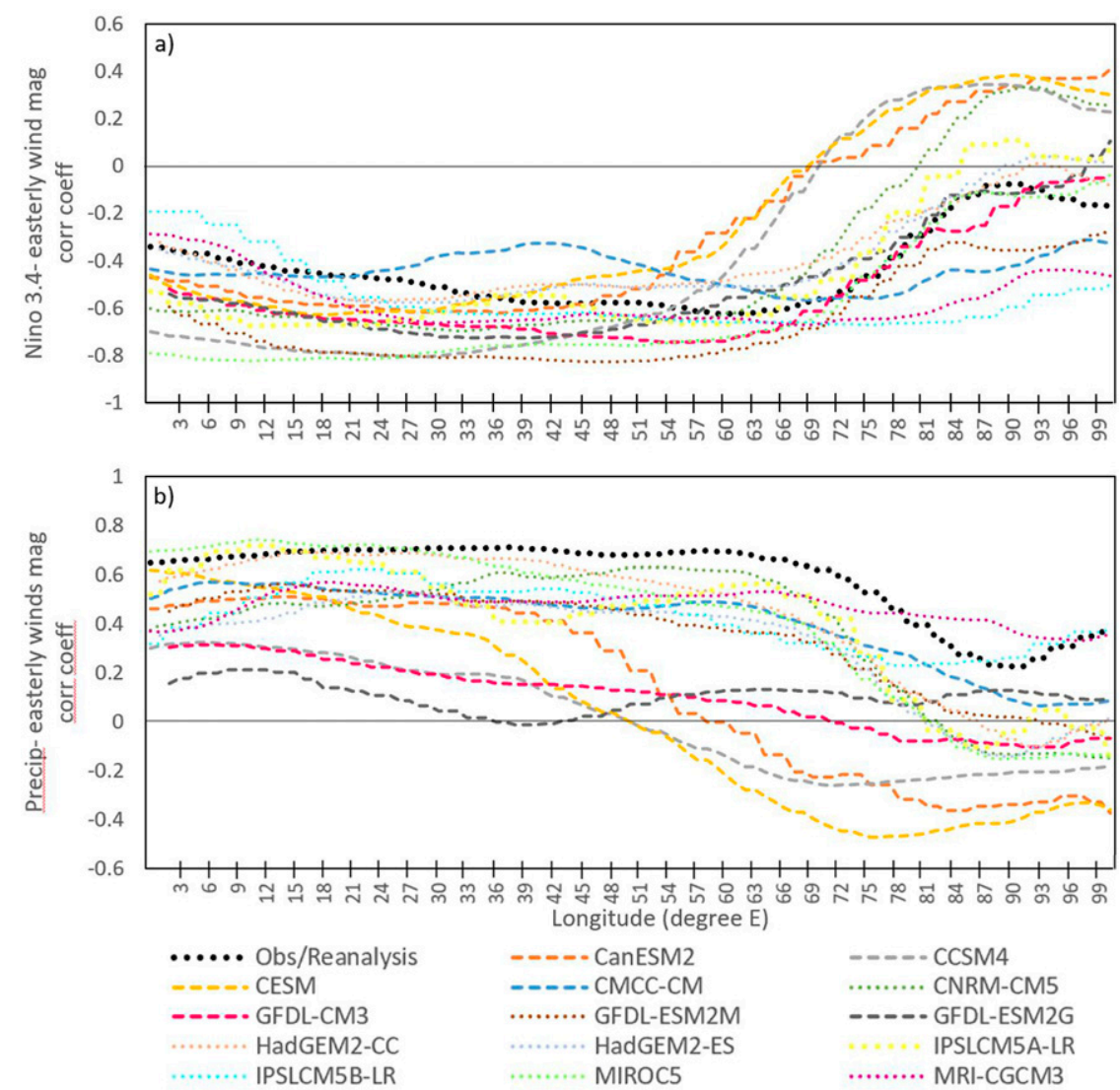

FIG. 7. (a) Longitudinal line plot showing Niño-3.4-U150 wind correlation (averaged over $5^{\circ}-15^{\circ} \mathrm{N}$; easterlies considered positive). (b) As in (a), but for SREA precipitation instead of Niño-3.4. The dashed lines (not dotted) show five models with lowest ENSO teleconnections; the rest of the models are dotted to ease visualization. Observations are shown in big black dotted lines.

Variability in TEJ-precipitation coupling still explains a large amount of cross-model variability in ENSO teleconnections (52\%) in the AMIP simulations. However, ENSO-TEJ variability explains more variability in AMIP (51\%) than in coupled simulations.
This is because certain models (CCSM4, MIROC5) that have low ENSO-SREA correlation in AMIP also have very low ENSOTEJ correlation. While it is surprising that the atmosphere-only versions of these models do not outperform the coupled version, it is
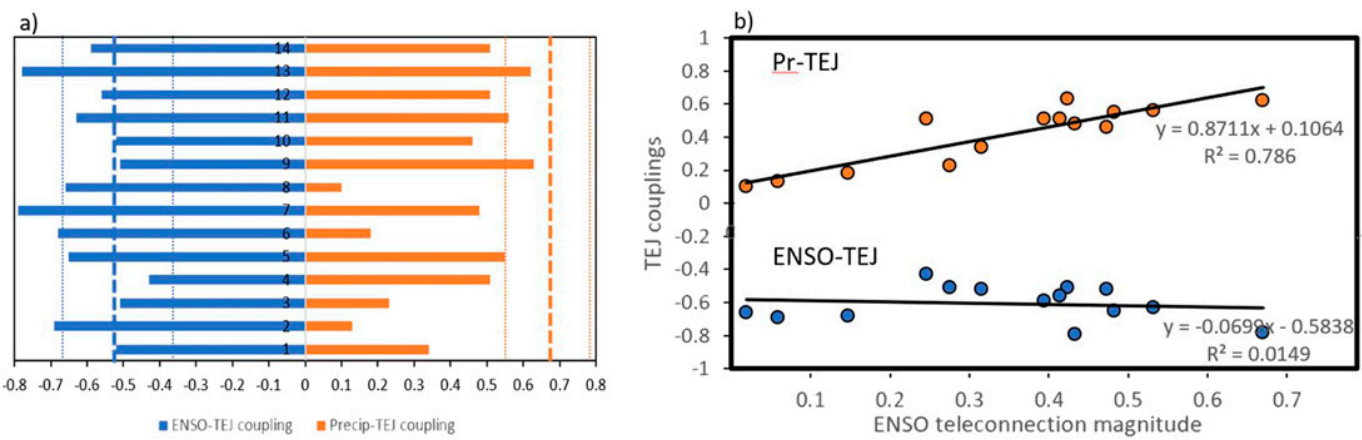

FIG. 8. (a) TEJ coupling with ENSO (blue bars) and precipitation (orange bars). Thick dashed vertical lines are the observed values, and thin dotted lines represent confidence intervals. Numbers are for models as shown in Table 1; (b) Scatterplot: $x$ axis is ENSO teleconnection magnitude, defined in text as the ENSO-SREA statistical relationship (values shown in Table 3, column 2), and $y$ axis is TEJ couplings shown in (a). 


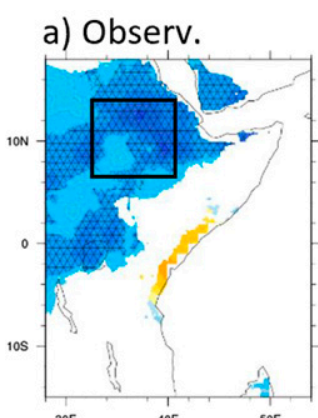

b) $\operatorname{CCSM} 4$

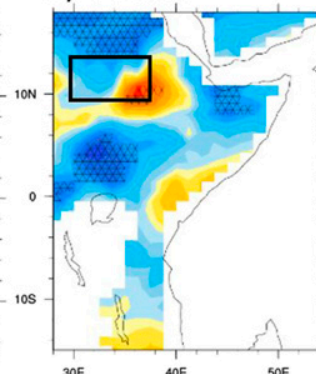

g) IPSL-CM5A-LR c) CESM

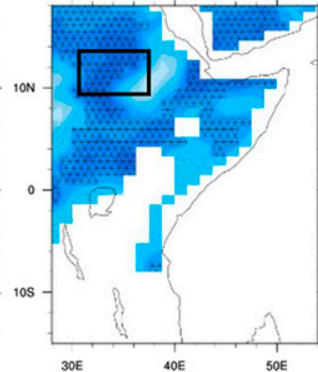

h) IPSL-CM5B-LR d) CMCC-CM

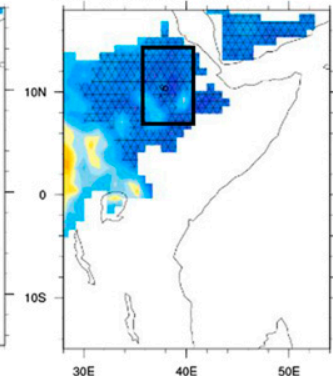

i) $M I R O C 5$
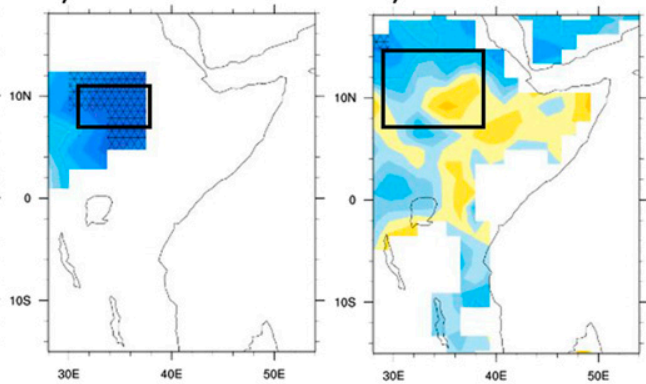

e) CNRM-CM5

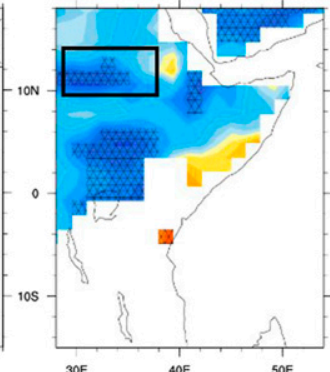

j) $\mathrm{MRI}-\mathrm{COE}$
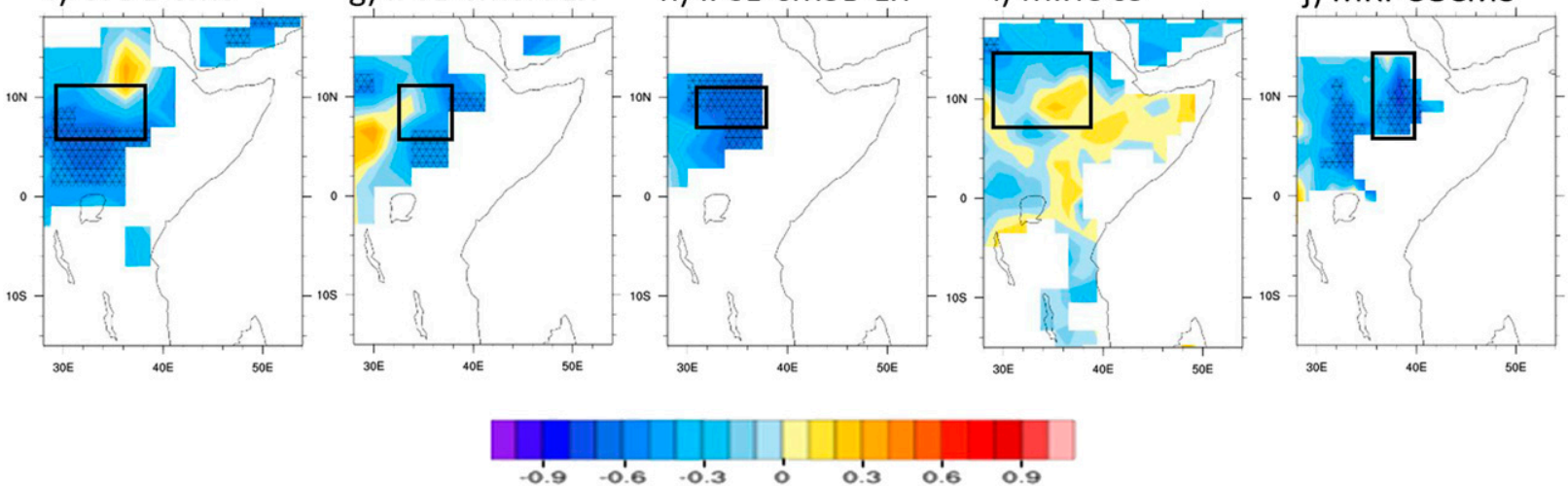

FIG. 9. Niño-3.4 linear correlation with precipitation for AMIP simulations. Areas with rainfall below $50 \mathrm{~mm}$ in the JAS season are suppressed, and hatching indicates significance.

not surprising that models whose TEJ does not respond accurately to ENSO also have weak ENSO-SREA teleconnections. Additionally, the magnitude of the peak TEJ winds also becomes important in explaining intermodel variability in correlations in AMIP (44\%) compared to $<1 \%$ in CMIP. Stronger winds at the core are associated with stronger ENSO-SREA correlations.

The decline in power of TEJ-SREA coupling in explaining cross-model variability in ENSO-SREA coupling relative to coupled simulations is largely driven by CCSM4 and CESM. Removing these models from the AMIP analysis improves the variability explained from $52 \%$ to $85 \%$ but also reduces the number of data points for study. MIROC5's decrease in AMIP simulations is surprising and possibly informative, as the decrease in ENSO-TEJ coupling is accompanied with a decrease in precipitation-TEJ coupling as well as overall ENSO teleconnections. It is also possible that the model might be heavily parameterized for ENSO in historical simulations such that it breaks when observed SSTs are imposed.

We note that the ENSO-TEJ coupling, TEJ-precipitation coupling, and peak wind speeds in the TEJ are themselves correlated with each other in AMIP. Such associations suggest there may be some common atmospheric mechanism at play. One possibility would be the response of deep convection to changes in SST. If this is unrealistically weak then one would expect both a weak Walker circulation and weak changes in

TABLE 4. AMIP table of two-way correlations for Niño-3.4, SREA, and TEJ: all significant correlations are in bold, and correlation no different from observed at ( $90 \%$ significance level, two-sided) are in italics.

\begin{tabular}{lcrr}
\hline \multicolumn{1}{c}{ Name } & Niño-3.4-SREA (I) & Niño-3.4-TEJ index (II) & SREA-TEJ index (III) \\
\hline Observations and reanalysis & $\mathbf{- 0 . 7 1}$ & $\mathbf{- 0 . 7 2}$ & $\mathbf{0 . 5 9}$ \\
CCSM4 & -0.11 & $\mathbf{- 0 . 4 1}$ & -0.28 \\
CESM & $-\mathbf{0 . 5 1}$ & -0.32 & 0.05 \\
CMCC-CM & $-\mathbf{0 . 6 6}$ & $-\mathbf{0 . 6 6}$ & $\mathbf{0 . 6 0}$ \\
CNRM-CM5 & $\mathbf{- 0 . 6 1}$ & $\mathbf{- 0 . 5 4}$ & $\mathbf{0 . 5 3}$ \\
GFDL CM3 & $-\mathbf{0 . 5 7}$ & $\mathbf{- 0 . 6 5}$ & $\mathbf{0 . 4 7}$ \\
IPSL-CM5A-LR & -0.41 & $\mathbf{- 0 . 7 3}$ & $\mathbf{0 . 5 2}$ \\
IPSL-CM5B-LR & $-\mathbf{0 . 7 3}$ & $\mathbf{- 0 . 6 7}$ & $\mathbf{0 . 6 6}$ \\
MIROC5 & 0.03 & -0.19 & 0.26 \\
MRI-CGCM3 & $\mathbf{- 0 . 7 1}$ & $\mathbf{- 0 . 6 0}$ & $\mathbf{0 . 7 2}$ \\
\hline
\end{tabular}



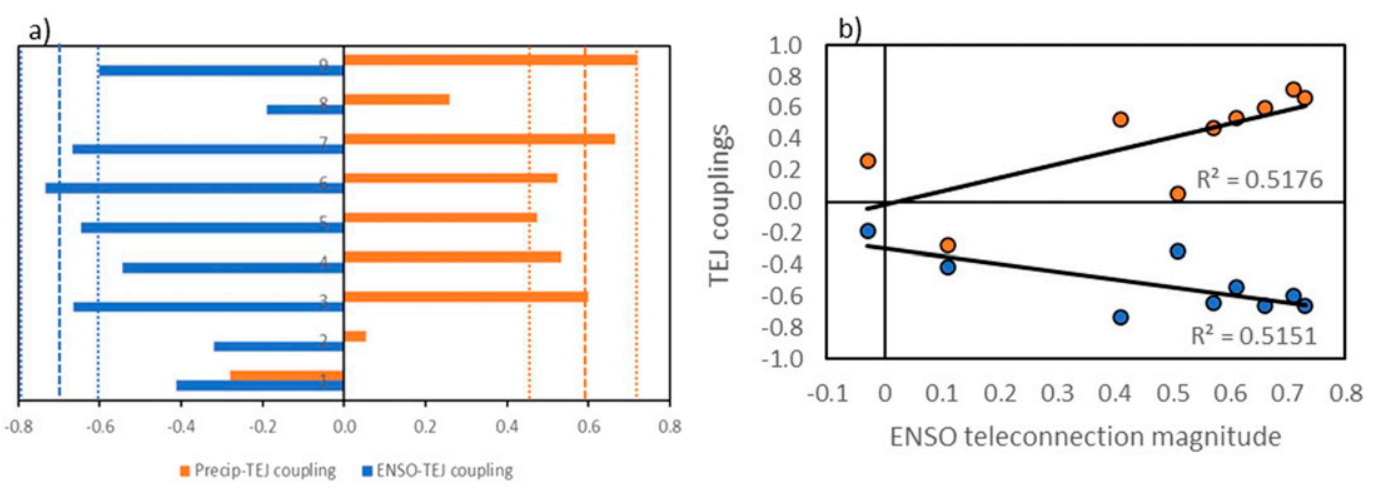

FIG. 10. AMIP simulations. (a) Bar graphs representing TEJ couplings with (left) ENSO and (right) SREA precipitation; thick dashed line shows observed value and think dotted lines show confidence intervals for observed value. (b) Scatterplots of TEJ couplings with ENSO teleconnection magnitude.

winds given changes in temperature. Another possibility is convective momentum transport-if this is overly strong, it would lead the correct pressure gradients to produce winds that are too weak. Without actually doing sensitivity studies within a single model, however, it is difficult to evaluate which mechanisms are most important.

\section{e. Mechanisms of TEJ influence}

The fact that intermodel variability in the TEJ-precipitation coupling explains intermodel variability of ENSO impact on SREA does not automatically mean that the mechanisms previously proposed for explaining the TEJ-precipitation relationship are valid. We investigate this by looking at the spatial structure of the jet couplings. If the TEJ-SREA coupling were driven by upper-level divergence at the jet exit, one would expect to see its footprint in large-scale upper-level deceleration of the jet in the vicinity of the eastern African summertime precipitation maximum. A decrease in zonal velocity in the jet is ultimately linked to meridional divergence. We define a TEJ_difference index (TEJ_diff1) as the difference between TEJ wind speeds east and west of the region of precipitation maximum. Drawing on previous studies ( $\mathrm{Li}$ et al. 2016) our eastern TEJ wind speed is calculated for $30^{\circ}-70^{\circ} \mathrm{E}$. Our western TEJ wind speed is calculated for $5^{\circ}-20^{\circ} \mathrm{E}$. We find very little association between the TEJ_diff1 index and eastern African JAS rainfall: the TEJ_diff1-SREA correlation explains only about $16 \%$ (2\%) of the variability in ENSO teleconnection in CMIP (AMIP) simulations. A second index (TEJ_diff2), calculated using more proximal TEJ averaging areas $\left(40^{\circ}-50^{\circ} \mathrm{E}\right.$ and $\left.20^{\circ}-30^{\circ} \mathrm{E}\right)$ explained only $6 \%(0 \%)$ of rainfall variability (Fig. 11). These weak results do not support the interpretation that an upper-level divergence mechanism is the sole or primary way in which the TEJ influences rainfall in this region. Since TEJ-SREA coupling explains difference in ENSO teleconnection across models, and TEJ_diff-precipitation coupling does not explain a large percentage of this difference, it appears that the upper-level divergence mechanism may not be the main or the only mechanism at play.

Observed values of precipitation correlation with the two TEJ differences for 1950 (1980)-2005 are $-0.38(-0.07)$ and -0.24 (0.04), respectively. The lack of consensus between two time periods is unsatisfying. In fact, the stronger correlations in 1950-2005 mostly arise from first 30 years, with values of -0.35 and -0.25 for the two difference indices. This points to limitations and inconsistencies in the reanalyses, or to nonstationarity in the recent record, and serves as a reminder to lower expectations from the GCMs.

Indeed, GCMs show broad range of values, varying both in sign and magnitude (Table S2). TEJ_diff1 correlations with SREA for a few notable models with highest ENSO teleconnection signals are 0.37 ( -0.04$)$ for CNRM-CM5 (AMIP), 0.10 (0.46) for IPSL-CM5A-LR (AMIP), and -0.25 (0.12) for MIROC5 (AMIP). The sign and magnitude difference in AMIP and CMIP simulations of a given model (say CNRM-CM5, which has good performance throughout) is also inconsistent.

Additionally, while climatological meridional divergence patterns in models are quite similar to the reanalyses (Fig. 12), with some variations in regional strength (Fig. S8), El Niño composites are visibly different. Figure 13 shows El Niño anomalies for one model from each modeling institute (the model with highest ENSO teleconnection shown; other models from the same institute were very similar), all of which underscore the absence of cross-model consistency: MIROC5 (which has the highest Niño3.4-precipitation correlation of -0.68) and CNRM-CM (correlation of -0.49 ) have anomalies over part of the SREA region; four out of five models with the lowest ENSO teleconnection (CanESM2, CCSM4, CESM, CMCC) show no anomalies over the region of interest, but GFDL CM3 (insignificant ENSO teleconnection) shows strong anomalies over a major part of its SREA. Five out of seven models with the strongest ENSO teleconnection (IPSL-CM5A-LR, IPSL-CM5B-LR, HadGEM2-ES, HadGEM2-CC, GFDL-ESM2M) show no divergence anomalies over the SREA region.

These inconsistencies suggest that divergence is not the primary means within the models by which TEJ strength and SREA precipitation are coupled. It is also noted that unlike meridional divergence, the zonal divergence over the SREA region varies among the reanalyses (Fig. S7), which is concerning and hinders next steps toward a more complete understanding. Total divergence (which is the sum of zonal and 

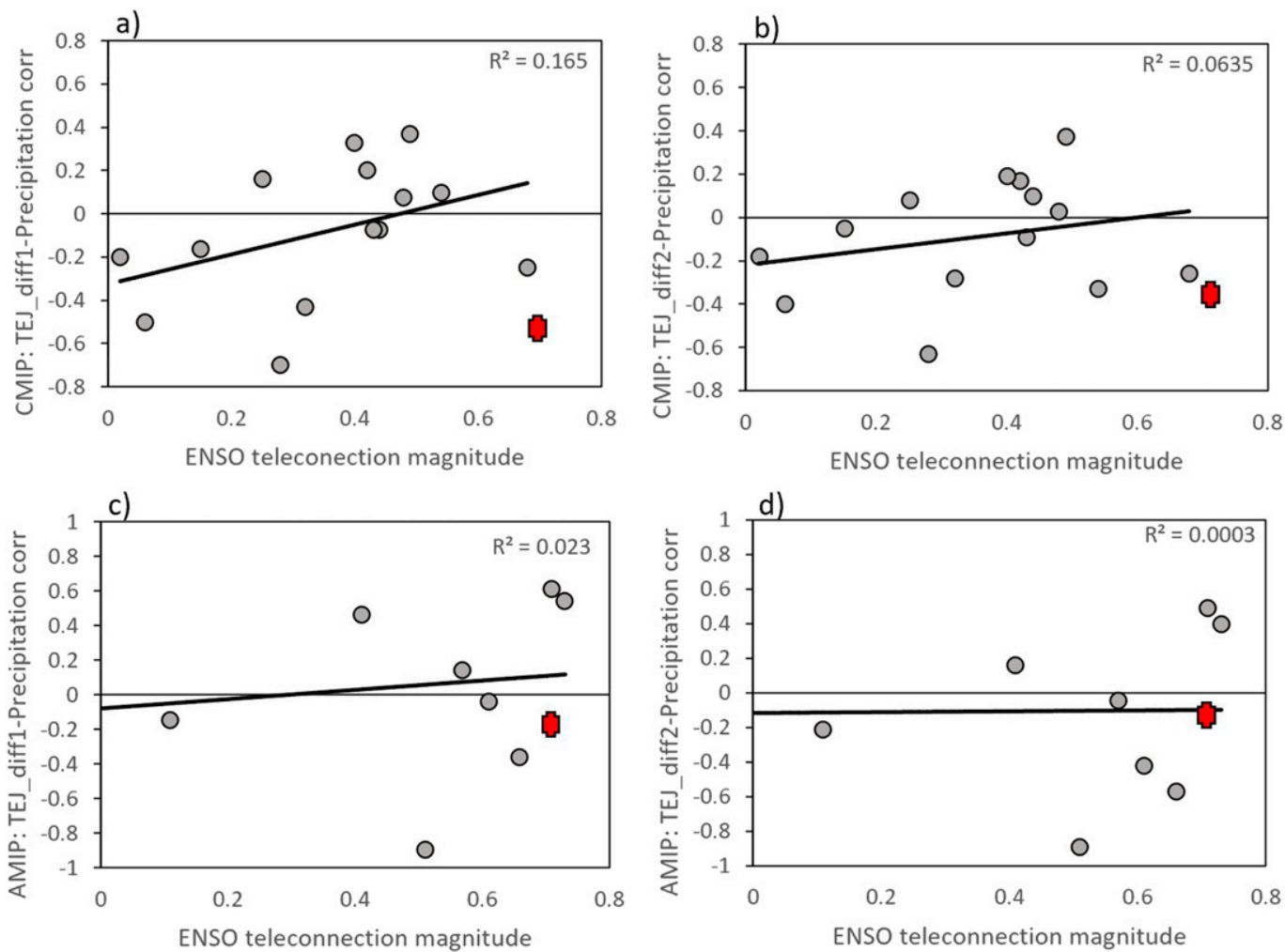

FIG. 11. Scatterplots showing (a),(c) TEJ_diff1-precipitation and (b),(d) TEJ_diff2-precipitation coupling with ENSO teleconnection for the models. Red cross shows the values for observations.

meridional divergence) thus also varies among the reanalysis products and could not be used to evaluate models effectively.

The weak relationship between TEJ divergence and SREA across models is consistent with the fact that, as shown in Fig. 7, TEJ winds over a broad swath of longitudes correlate with SREA. Looking at the TEJ upstream and downstream of SREA individually (Table 5), we see that the coupling between immediately downstream $\left(20^{\circ}-30^{\circ} \mathrm{E}\right)$ wind speeds and SREA explains a larger portion of intermodel variability in ENSO teleconnections $(83 \%)$ than the coupling with immediately upstream $\left(40^{\circ}-50^{\circ} \mathrm{E}\right)$ wind speeds, which is $65 \%$. We do not have an explanation for the fact that the outflow from the region is more tightly coupled to the SREA than the inflow. Larger upstream and downstream regions (as used in TEJ_diff1) explain a) NCEP/NCAR Clim

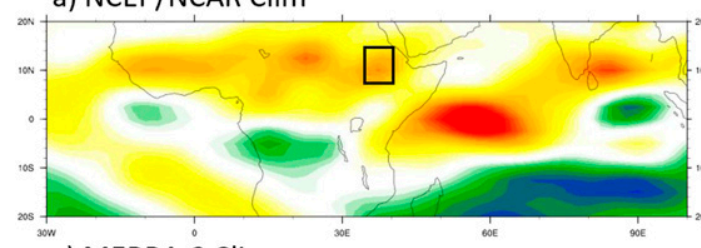

c) MERRA-2 Clim

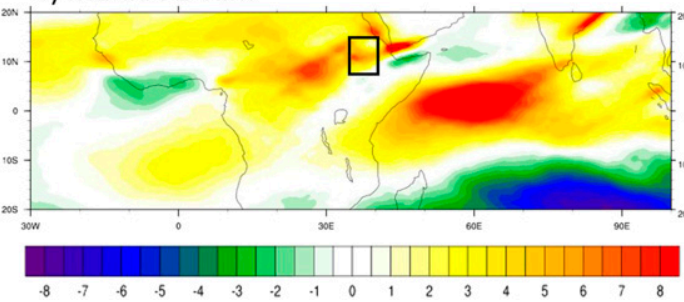

b) NCEP/NCAR EI Nino

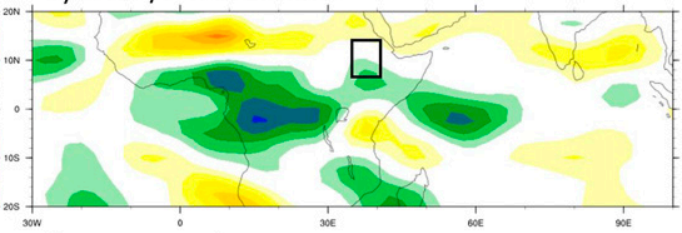

d) MERRA-2 El Nino

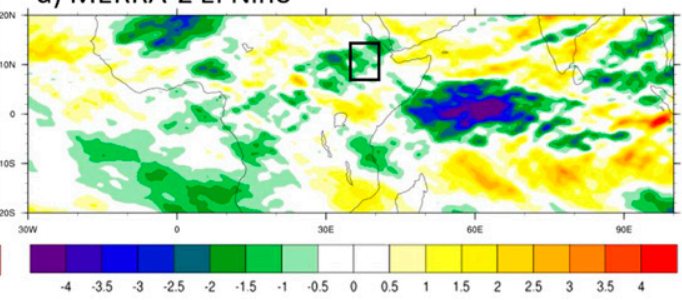

FIG. 12. Meridional divergence ( $d v / d y$ ) for two reanalysis products (rows), showing (a),(c) climatology and (b),(d) El Niño anomalies; units are $10^{-6} \mathrm{~s}^{-1}$. 
a) CanESM2

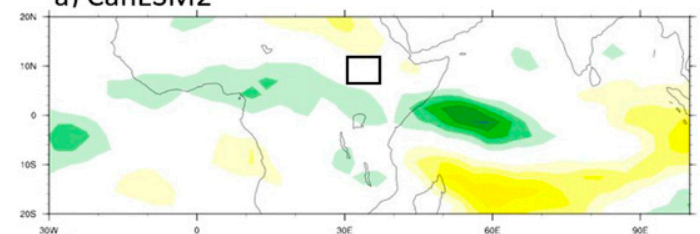

c) CMCC-CM

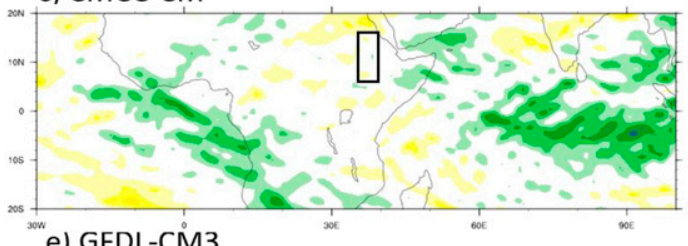

e) GFDL-CM̉3

\section{b) CCSM4}

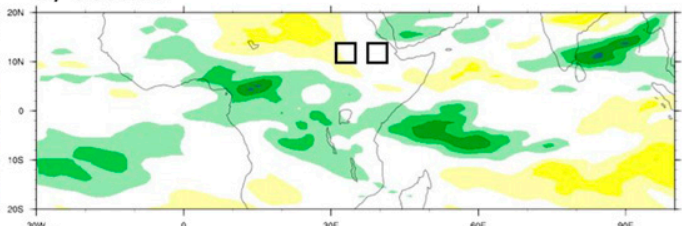

d) CNRM-CM5

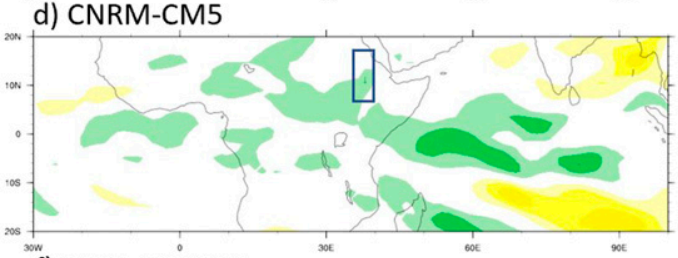

f) GFDL-ESM $2 M$

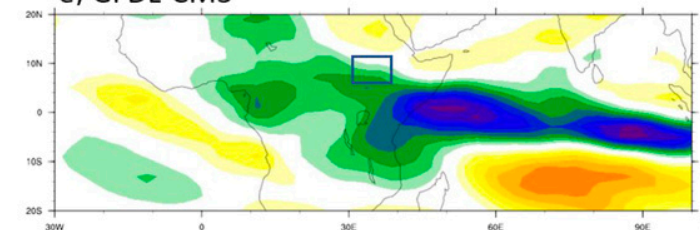

g) HadGEM2-ES

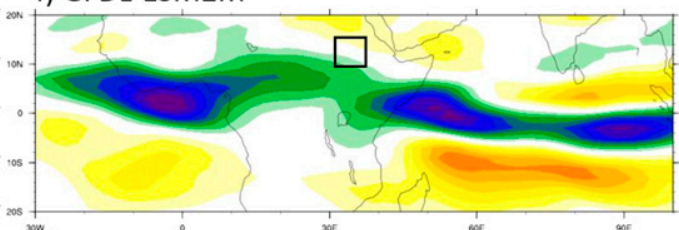

h) IPSL-CM5ंA-LR
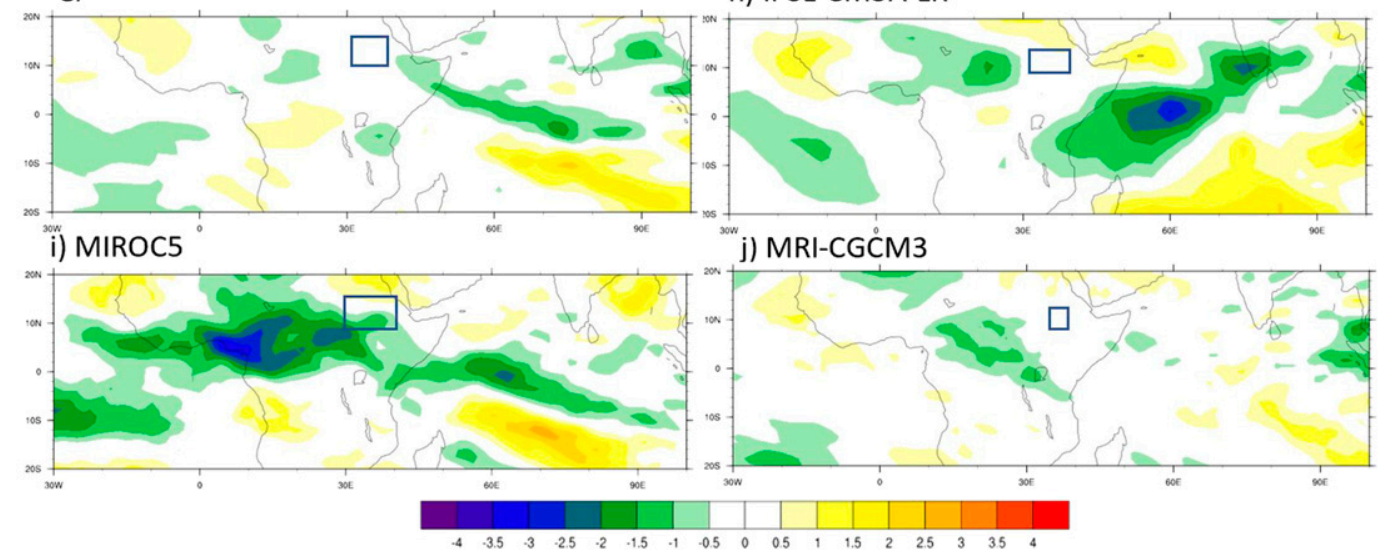

FIG. 13. Meridional divergence El Niño anomalies $\left(10^{-6} \mathrm{~s}^{-1}\right)$.

$66 \%$ and $69 \%$, respectively. This is noticeably lower than the variability explained by the entire domain $\left(5^{\circ}-65^{\circ} \mathrm{E} ; 78.6 \%\right)$. Intermodel differences in regional ENSO-TEJ couplings in all cases explain virtually none of the intermodel variability, except when a larger eastern upstream region is used, in which case it is $32 \%$. One reason for the latter could be due to four (CanESM2, CCSM4, CESM, GFDL-ESM2G; 4/14 × $100=29 \%)$ of the models having a westward shifted correlation structure of pan-tropical circulation and low ENSOSREA coupling, as explained previously.

\section{f. Other mechanisms: Somali jet and African easterly jet}

Our analysis has focused on TEJ-mediated connections between ENSO and SREA, as this is one of the mechanisms emphasized in recent studies of the region. However, the TEJ is not the only potential vehicle for ENSO influence on the region. In particular, the Somali jet (or East African low-level jet $)$, a low-level jet $(850 \mathrm{mb} ; 1 \mathrm{hPa}=1 \mathrm{mb})$ over the western Indian Ocean, can influence rainfall in the region through moisture supply and lower-level convergence (Fig. 14a; Segele et al. 2009; Berhane et al. 2014). The average wind speed right before this jet enters into the SREA region (Fig. 14b) is significantly correlated with both Niño-3.4 (-0.4) and precipitation (0.41), although not as strongly as the TEJ. As is the case for the TEJ, models are better at capturing ENSO-jet associations, but struggle to capture jet-precipitation associations (Fig. 14c). Additionally, the Somali jet-precipitation (Somali jet-ENSO) correlation explains 44\% (3\%) of intermodel variability of the ENSO teleconnection (Fig. 14d), which is less than what is explained by TEJ. Interestingly, both the jets' couplings in models are highly correlated (0.8), which is consistent with the fact that the jets are strongly correlated with each other (0.65) in the observations. Previous studies focusing on the South Asian monsoon (Abish et al. 2013) have called the TEJ and Somali jet the upper and lower limb of the Walker circulation, respectively. A related factor is the low-level Turkana jet, a mesoscale feature whose magnitude could be linked to Somali jet and has been associated with diminished 
TABLE 5. Different TEJ indices, their observed couplings, and percent of cross-model variability explained in ENSO teleconnection.

\begin{tabular}{lccc}
\hline \hline \multicolumn{1}{c}{ TEJ index } & $\begin{array}{c}\text { Observed TEJ coupling } \\
\text { (ENSO/precipitation) }\end{array}$ & $\begin{array}{c}\text { Cross-model variability in } \\
\text { ENSO teleconnection explained by } \\
\text { ENSO-TEJ coupling }\end{array}$ & $\begin{array}{c}\text { Cross-model variability in ENSO } \\
\text { teleconnection explained by } \\
\text { precipitation-TEJ coupling }\end{array}$ \\
\hline TEJ $\left(5^{\circ}-65^{\circ} \mathrm{E}\right)$ & $-0.53 / 0.69$ & $1.5 \%$ & $78.6 \%$ \\
TEJ_east1 $\left(30^{\circ}-70^{\circ} \mathrm{E}\right)$ & $-0.58 / 0.69$ & $32.2 \%$ & $66.3 \%$ \\
TEJ_east2 $\left(40^{\circ}-50^{\circ} \mathrm{E}\right)$ & $-0.58 / 0.69$ & $1.9 \%$ & $65.0 \%$ \\
TEJ_west $\left(5^{\circ}-20^{\circ} \mathrm{E}\right)$ & $-0.42 / 0.68$ & $0.3 \%$ & $69.3 \%$ \\
TEJ_west2 $\left(20^{\circ}-30^{\circ} \mathrm{E}\right)$ & $-0.48 / 0.70$ & $0 \%$ & $83.3 \%$ \\
\hline
\end{tabular}

summer rainfall in parts of eastern Africa (Nicholson 2016; Vizy and Cook 2019). Last, the African easterly jet (AEJ) magnitude is also correlated with precipitation $(-0.55$; reversal in sign implies the opposite effect from these midlevel easterlies), but not so strongly with ENSO (0.16). The AEJprecipitation correlation explains $55 \%$ of the intermodal ENSO teleconnection. Interestingly, TEJ-AEJ shear (calculated by differencing the wind speeds of the two jets) coupling with SREA improves the magnitude of cross-model variability explained in ENSO teleconnections (calculated from $R^{2}$ for a linear regression of ENSO teleconnection against shearSREA coupling for all the models) to $84 \%$. This is not significantly higher than the variability explained by TEJ alone (79\%), but it does suggest that shear could be a mechanism through which jets influence SREA.

We have not separately analyzed the Indian Ocean dipole (IOD) in this study for two reasons: 1) Observed correlation of SREA with IOD for 1950 (1900)-2005 is $-0.25(-0.10)$, which is relatively small compared to ENSO, and 2) ENSO is significantly related to IOD at $0.42(0.36)$ correlation coefficient, which means that removing IOD years from ENSO composites limited the number of years for study (often to fewer than three strong El Niño years), which would compromise our ENSO analysis. Nonetheless, it is possible that the IOD complements ENSO's impact, which may mean that ENSO's true impact on TEJ is lower than shown.

\section{Conclusions}

We have argued that models differ in their coupling between ENSO and SREA primarily because of differences in the extent to which TEJ couples with precipitation in these models. The TEJ (strongly modulated by ENSO) has a stronger correlation with SREA than both the Somali jet (moderately modulated by ENSO) and African easterly jet (weakly modulated by ENSO). Differences in TEJ coupling with precipitation across models explain the majority (about $80 \%$ ) of variability in ENSO teleconnection simulation across the models, which is also higher than same results using the Somali jet (44\%) and African easterly jet (55\%) couplings. Models have a more robust representation of jet coupling with ENSO than with precipitation. Thus, given that ENSO is linearly associated with $50 \%$ of interannual rainfall variability, the latter is a limitation to accurately predicting future precipitation changes. A previous study by Whittleston et al. (2017) showed similar results for regional jets (including the TEJ) and rainfall coupling over West Africa.
Our results also have implications for which models should be selected for projecting future changes in SREA. In addition to having a good SREA climatology, models should have both realistic ENSO-SREA teleconnection and realistic TEJ-SREA association. This is consistent with the argument of Nicholson (2014), who found atmospheric variables that teleconnect largescale signals like sea surface temperature provide higher forecast skills in observational analysis than do sea surface temperatures alone. Within our model suite, CNRM-CM5, IPSL-CM5B-LR, and HadGEM2-CC were the best-performing models, with realistic SREA-TEJ associations in both the coupled and AMIP versions of the model.

The association between the TEJ and SREA is spatially complex. The spatial location of TEJ maximum with respect to precipitation region matters for both ENSO teleconnection (maximum zonal wind longitude explains $30 \%$ of the variability) and TEJ-precipitation coupling (maximum zonal wind longitude explains $50 \%$ of the variability). However, while previous studies have mostly highlighted significant correlations with the jet core region, we found that correlations steadily increase westward of southern India and reach their highest values slightly westward of the core, until they decrease again over the Atlantic coast of Africa. The way the jet is represented across longitudes seems to be important, and defining TEJ influence in these terms reveals a stronger role in cross-model variability in ENSO teleconnections ( $80 \%$ ) than when one considers only the TEJ core in the Arabian Sea (50\%).

The fact that the TEJ-precipitation relationship explains so much of the cross-model variation strongly suggests that there is a robust mechanism that underlies this association. However, our diagnostics of the leading hypothesized mechanism-variability in divergence in the TEJ exit region-are inconclusive at best. If divergence were the dominant driver, we would expect to see better correlation of regional rainfall with the difference between the TEJ_east and TEJ_west indices. We do not. The first 30 years of reanalysis shows a negative association, but if meridional divergence were indeed the responsible mechanism of impact on rainfall, we would expect a positive correlation. If we disregard first 30 years of reanalysis, the values are close to zero. Both TEJ_diff indices showed similar results, and no consistent pattern among "good" and "bad" models. Even for just the models with teleconnections on the better end of the spectrum, TEJ_diff associations include negative, zero, and positive values. Additionally, meridional divergence anomalies do not convey a consistent proof of connection. This suggests that there might be other mechanisms at play. 
a)

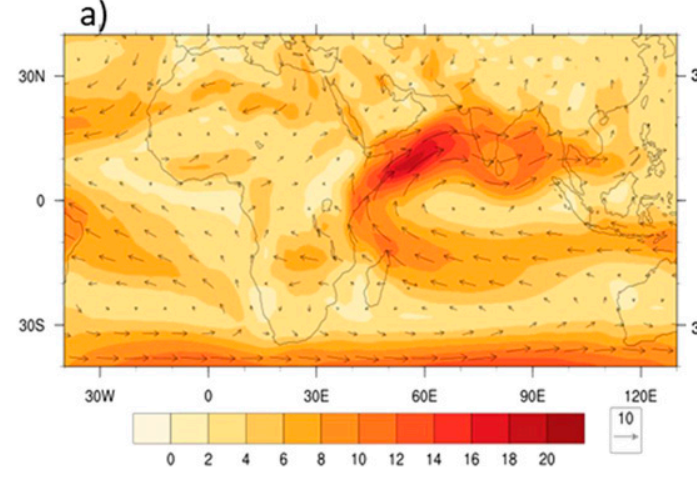

b)

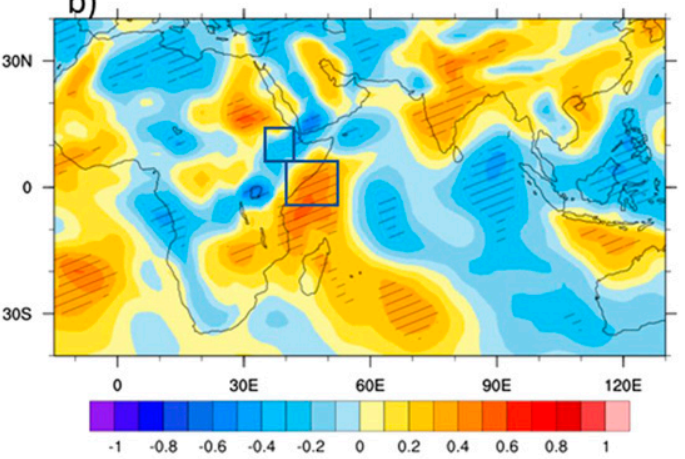

c)

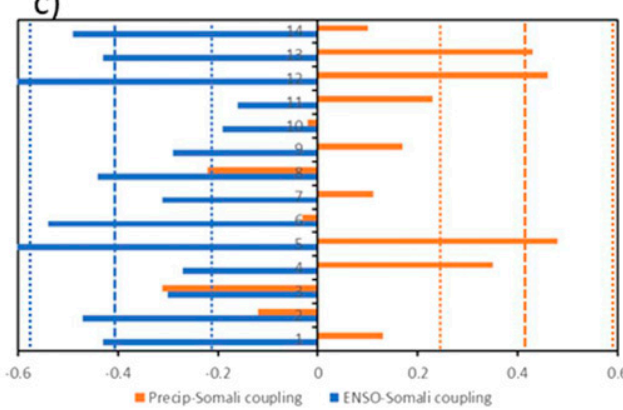

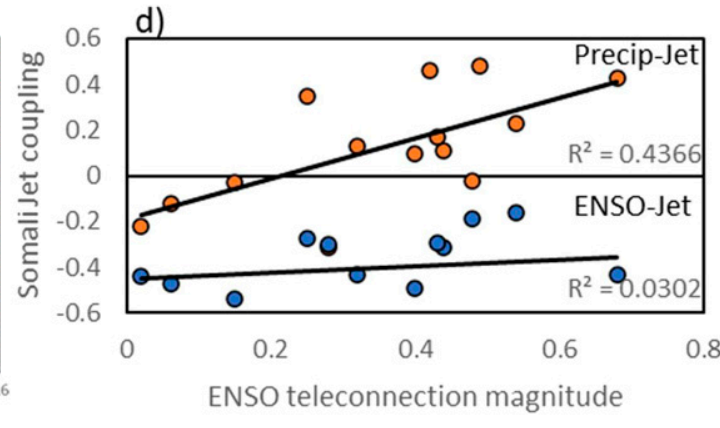

FIG. 14. (a) Somali jet climatological JAS wind speed at $850 \mathrm{hPa}\left(\mathrm{m} \mathrm{s}^{-1}\right)$, colors showing wind magnitudes. (b) SREA correlation with Somali jet meridional winds. (c) Somali jet couplings with ENSO and precipitation; the thick dashed line is observations with its confidence interval given by thin dotted lines. (e) Scatterplot between Somali jet couplings and ENSO teleconnection magnitude.

For West Africa, a recent study by Lemburg et al. (2019) questioned the upper-level divergence mechanism of TEJ influence on rainfall, but this was at intraseasonal time scale and mesoscale convective rainfall preceded changes in TEJ. We speculate that TEJ-SREA coupling could be explained by other likely (possibly nonexclusive) mechanisms: 1) interaction with the African easterly jet to reduce relative upper-level shear that could enhance stratiform rains (Schumacher and Houze 2006) [we do see a high percent variability explained by wind shear $(84 \%)$, although it is not significantly higher than TEJ alone (79\%)]; 2) baroclinic instability of the zonal jet leading to waves [Nicholson et al. (2007) showed the existence of planetary waves at TEJ level over West Africa using numerical simulations as well as reanalysis]; and 3) variations in temperature change aloft linked to TEJ, which could impact stability of the atmosphere over eastern Africa. These hypotheses, among others, can be tested in future studies to investigate mechanisms of TEJ influence that are not documented in the literature.

Of course, correlations do not imply causality. It is possible that ENSO changes both TEJ and SREA synchronously, and that they are not causally linked to each other. Other possibilities are that the direction of influence is from precipitation to TEJ rather than the other way around, or that the TEJprecipitation interaction is not a one-way interaction but involves both influencing each other. Rao and Srinivasan (2016) showed that latent heating (due to precipitating clouds) over India can impact the location and strength of the TEJ. Redelsperger et al. (2002) proposed that latent heat released by convection can enhance upper-level shear, and therefore enhance the TEJ. However, Nicholson and Klotter (2020) provided evidence to the contrary, showing that the magnitude of TEJ is not a response to variations in rainfall over West Africa. According to quasigeostrophic theory, the jet is associated with ageostrophic flows in the exit region (Uccellini and Johnson 1979), with divergence southwest of jet exit region (see Lemburg et al. 2019, their Fig. 3), as seen in climatology, but the question is if the resulting divergence provides a sufficient upward pull of moist air at the surface. A deeper understanding of the mechanisms and directionality of TEJ-East African summer precipitation association should be a priority for studies of climate variability and change in the region.

Acknowledgments. This research was supported by the U.S. National Science Foundation (NSF) under Grant BCS1639214.

\section{REFERENCES}

Abish, B., P. V. Joseph, and O. M. Johannessen, 2013: Weakening trend of the tropical easterly jet stream of the boreal summer monsoon season 1950-2009. J. Climate, 26, 9408-9414, https:// doi.org/10.1175/JCLI-D-13-00440.1.

Berhane, F., B. Zaitchik, and A. Dezfuli, 2014: Subseasonal analysis of precipitation variability in the Blue Nile River Basin. J. Climate, 27, 325-344, https://doi.org/10.1175/JCLI-D-13-00094.1. 
Bhattacharjee, P. S., and B. F. Zaitchik, 2015: Perspectives on CMIP5 model performance in the Nile River headwaters regions. Int. J. Climatol., 35, 4262-4275, https://doi.org/10.1002/joc.4284.

Block, P., and B. Rajagopalan, 2007: Interannual variability and ensemble forecast of Upper Blue Nile Basin Kiremt season precipitation. J. Hydrometeor., 8, 327-343, https://doi.org/ 10.1175/JHM580.1.

Cai, W., and Coauthors, 2014: Increasing frequency of extreme El Niño events due to greenhouse warming. Nat. Climate Change, 4, 111-116, https://doi.org/10.1038/nclimate2100.

Camberlin, P., 1995: June-September rainfall in north-eastern Africa and atmospheric signals over the tropics: A zonal perspective. Int. J. Climatol., 15, 773-783, https://doi.org/10.1002/ joc.3370150705.

Chen, T. C., 1980: On the energy exchange between the divergent and rotational components of atmospheric flow over the tropics and subtropics at $200 \mathrm{mb}$ during two northern summers. Mon. Wea. Rev., 108, 896-912, https://doi.org/10.1175/ 1520-0493(1980)108<0896:OTEEBT>2.0.CO;2.

— easterly jet. Mon. Wea. Rev., 115, 1739-1759, https://doi.org/ 10.1175/1520-0493(1987)115<1739:IVOTTE > 2.0.CO;2.

Conway, D., 2000: The climate and hydrology of the Upper Blue Nile River. Geogr. J., 166, 49-62, https://doi.org/10.1111/ j.1475-4959.2000.tb00006.x.

Diro, G. T., D. I. F. Grimes, and E. Black, 2011a: Teleconnections between Ethiopian summer rainfall and sea surface temperature: Part I-Observation and modelling. Climate Dyn., 37, 103-119, https://doi.org/10.1007/s00382-010-0837-8.

— — - and —, 2011b: Large scale features affecting Ethiopian rainfall. African Climate and Climate Change, C. J. R. Williams and D. R. Kniveton, Eds., Springer, 13-50.

Flato, G., and Coauthors, 2013: Evaluation of climate models. Climate Change 2013: The Physical Science Basis, T. F. Stocker et al., Eds., Cambridge University Press, 741-866.

Flohn, H., 1964: Investigations on the tropical easterly jet. Bonn. Meteor. Abh., 4, 1-83.

Fordham, D. A., T. M. Wigley, M. J. Watts, and B. W. Brook, 2012: Strengthening forecasts of climate change impacts with multi-model ensemble averaged projections using MAGICC/SCENGEN 5.3. Ecography, 35, 4-8, https://doi.org/10.1111/j.1600-0587.2011.07398.x.

Funk, C., S. E. Nicholson, M. Landsfeld, D. Klotter, P. Peterson, and L. Harrison, 2015: The Centennial Trends Greater Horn of Africa precipitation dataset. Sci. Data, 2, 150050, https:// doi.org/10.1038/sdata.2015.50.

Gelaro, R., and Coauthors, 2017: The Modern-Era Retrospective Analysis for Research and Applications, version 2 (MERRA-2). J. Climate, 30, 5419-5454, https://doi.org/10.1175/JCLI-D-16-0758.1.

Gissila, T., E. Black, D. I. F. Grimes, and J. M. Slingo, 2004: Seasonal forecasting of the Ethiopian summer rains. Int. J. Climatol., 24, 1345-1358, https://doi.org/10.1002/JOC.1078.

Gleixner, S., N. Keenlyside, E. Viste, and D. Korecha, 2017: The El Niño effect on Ethiopian summer rainfall. Climate Dyn., 49, 1865-1883, https://doi.org/10.1007/s00382-016-3421-z.

Goswami, B. N., and P. K. Xavier, 2005: ENSO control on the South Asian monsoon through the length of the rainy season. Geophys. Res. Lett., 32, L18717, https://doi.org/10.1029/2005GL023216.

Grist, J. P., and S. E. Nicholson, 2001: A study of the dynamic factors influencing the rainfall variability in the West African Sahel. J. Climate, 14, 1337-1359, https://doi.org/10.1175/15200442(2001)014<1337:ASOTDF>2.0.CO;2.

Hastenrath, S., 1991: Climate Dynamics of the Tropics. Kluwer Academic, 488 pp.
Hemer, M. A., Y. Fan, N. Mori, A. Semedo, and X. L. Wang, 2013: Projected changes in wave climate from a multi-model ensemble. Nat. Climate Change, 3, 471-476, https://doi.org/ 10.1038/nclimate1791.

Huang, S., Z. Wen, Z. Chen, X. Li, R. Chen, and Y. Guo, 2019: Interdecadal change in the relationship between the tropical easterly jet and tropical sea surface temperature anomalies in boreal summer. Climate Dyn., 53, 2119-2131, https://doi.org/ 10.1007/S00382-019-04801-5.

Hulme, M., and N. Tosdevin, 1989: The tropical easterly jet and Sudan rainfall: A review. Theor. Appl. Climatol., 39, 179-187, https://doi.org/10.1007/BF00867945.

James, R., and Coauthors, 2018: Evaluating climate models with an African lens. Bull. Amer. Meteor. Soc., 99, 313-336, https:// doi.org/10.1175/BAMS-D-16-0090.1.

Jury, M. R., 2015: Statistical evaluation of CMIP5 climate change model simulations for the Ethiopian highlands. Int. J. Climatol., 35, 37-44, https://doi.org/10.1002/joc.3960.

Kharin, V. V., F. W. Zwiers, X. Zhang, and M. Wehner, 2013: Changes in temperature and precipitation extremes in the CMIP5 ensemble. Climatic Change, 119, 345-357, https:// doi.org/10.1007/s10584-013-0705-8.

Korecha, D., and A. G. Barnston, 2007: Predictability of JuneSeptember rainfall in Ethiopia. Mon. Wea. Rev., 135, 628-650, https://doi.org/10.1175/MWR3304.1.

Koteswaram, P., 1958: The easterly jet stream in the tropics. Tellus, 10, 43-57, https://doi.org/10.3402/tellusa.v10i1.9220.

Krishnamurti, T. N., 1971: Observational study of the tropical upper tropospheric motion field during the Northern Hemisphere summer. J. Appl. Meteor., 10, 1066-1096, https://doi.org/10.1175/ 1520-0450(1971)010<1066:OSOTTU>2.0.CO;2.

Lemburg, A., J. Bader, and M. Claussen, 2019: Sahel rainfalltropical easterly jet relationship on synoptic to intraseasonal time scales. Mon. Wea. Rev., 147, 1733-1752, https://doi.org/ 10.1175/MWR-D-18-0254.1.

Li, L., W. Li, T. Ballard, G. Sun, and M. Jeuland, 2016: CMIP5 model simulations of Ethiopian Kiremt-season precipitation: Current climate and future changes. Climate Dyn., 46, 28832895, https://doi.org/10.1007/s00382-015-2737-4.

Liu, Y., B. Hoskins, and M. Blackburn, 2007: Impact of Tibetan orography and heating on the summer flow over Asia. J. Meteor. Soc. Japan, 85, 1-19, https://doi.org/10.2151/jmsj.85.1.

Nicholson, S. E., 2014: The predictability of rainfall over the Greater Horn of Africa. Part I: Prediction of seasonal rainfall. J. Hydrometeor., 15, 1011-1027, https://doi.org/10.1175/JHM-D-13-062.1.

, 2016: The Turkana low-level jet: Mean climatology and association with regional aridity. Int. J. Climatol., 36, 2598-2614, https://doi.org/10.1002/joc.4515.

— , and D. Klotter, 2020: The tropical easterly jet over Africa, its representation in six reanalysis products, and its association with Sahel rainfall. Int. J. Climatol., https://doi.org/10.1002/ JOC.6623, in press.

, A. I. Barcilon, M. Challa, and J. Baum, 2007: Wave activity on the tropical easterly jet. J. Atmos. Sci., 64, 2756-2763, https:// doi.org/10.1175/JAS3946.1.

Nithya, K., M. G. Manoj, and K. Mohankumar, 2017: Effect of El Niño/La Niña on tropical easterly jet stream during Asian summer monsoon season. Int. J. Climatol., 37, 4994-5004, https://doi.org/10.1002/joc.5137.

Otieno, V. O., and R. O. Anyah, 2013: CMIP5 simulated climate conditions of the Greater Horn of Africa (GHA). Part I: Contemporary climate. Climate Dyn., 41, 2081-2097, https:// doi.org/10.1007/s00382-012-1549-z. 
Randall, D. A., and Coauthors, 2007: Climate models and their evaluation. Climate Change 2007: The Physical Science Basis, S. Solomon et al., Eds., Cambridge University Press, 589-662.

Rao, S., and J. Srinivasan, 2016: The impact of latent heating on the location and strength of the tropical easterly jet. Meteor. Atmos. Phys., 128, 247-261, https://doi.org/10.1007/s00703015-0407-z.

Redelsperger, J. L., A. Diongue, A. Diedhiou, J. P. Ceron, M. Diop, J. F. Gueremy, and J. P. Lafore, 2002: Multi-scale description of a Sahelian synoptic weather system representative of the West African monsoon. Quart. J. Roy. Meteor. Soc., 128, 12291257, https://doi.org/10.1256/003590002320373274.

Rowell, D. P., 2013: Simulating SST teleconnections to Africa: What is the state of the art? J. Climate, 26, 5397-5418, https:// doi.org/10.1175/JCLI-D-12-00761.1.

Schumacher, C., and R. A. Houze Jr., 2006: Stratiform precipitation production over sub-Saharan Africa and the tropical East Atlantic as observed by TRMM. Quart. J. Roy. Meteor. Soc., 132, 2235-2255, https://doi.org/10.1256/QJ.05.121.

Segele, Z. T., and P. J. Lamb, 2005: Characterization and variability of Kiremt rainy season over Ethiopia. Meteor. Atmos. Phys., 89, 153-180, https://doi.org/10.1007/s00703-005-0127-x.

,$- \ldots$, and L. M. Leslie, 2009: Large-scale atmospheric circulation and global sea surface temperature associations with Horn of Africa June-September rainfall. Int. J. Climatol., 29, 1075-1100, https://doi.org/10.1002/JOC.1751.

Seleshi, Y., and G. R. Demaree, 1995: Rainfall variability in the Ethiopian and Eritrean highlands and its links with the Southern Oscillation Index. J. Biogeogr., 22, 945-952, https:// doi.org/10.2307/2845995.

Shaman, J., and E. Tziperman, 2005: The effect of ENSO on Tibetan Plateau snow depth: A stationary wave teleconnection mechanism and implications for the South Asian monsoons. J. Climate, 18, 2067-2079, https://doi.org/10.1175/JCLI3391.1.

Siam, M. S., and E. A. Eltahir, 2017: Climate change enhances interannual variability of the Nile River flow. Nat. Climate Change, 7, 350-354, https://doi.org/10.1038/nclimate3273.

Slingo, J., H. Spencer, B. Hoskins, P. Berrisford, and E. Black, 2005: The meteorology of the western Indian Ocean, and the influence of the East African Highlands. Philos. Trans. Roy. Soc. London, 363A, 25-42, https://doi.org/10.1098/RSTA.2004.1473.

Smith, T. M., R. W. Reynolds, T. C. Peterson, and J. Lawrimore, 2008: Improvements to NOAA's historical merged land-ocean surface temperature analysis (1880-2006). J. Climate, 21, 22832296, https://doi.org/10.1175/2007JCLI2100.1.

Tadesse, T., 1994: Summer monsoon seasonal rainfall of Ethiopia in ENSO episodic years. Proc. WMO/TOGA Int. Conf. on Monsoon Variability and Prediction, Trieste, Italy, WMO, 48-55.

Taylor, K. E., R. J. Stouffer, and G. A. Meehl, 2012: An overview of CMIP5 and the experiment design. Bull. Amer. Meteor. Soc., 93, 485-498, https://doi.org/10.1175/BAMS-D-11-00094.1.

Tierney, J. E., C. C. Ummenhofer, and P. B. deMenocal, 2015: Past and future rainfall in the Horn of Africa. Sci. Adv., 1, e1500682, https://doi.org/10.1126/sciadv.1500682.

Trenberth, K. E., 1997: The definition of El Niño. Bull. Amer. Meteor. Soc., 78, 2771-2778, https://doi.org/10.1175/15200477(1997)078<2771:TDOENO > 2.0.CO;2.

Uccellini, L. W., and D. R. Johnson, 1979: The coupling of upper and lower tropospheric jet streaks and implications for the development of severe convective storms. Mon. Wea. Rev., 107, 682-703, https:// doi.org/10.1175/1520-0493(1979)107<0682:TCOUAL >2.0.CO;2.

Verdin, J., C. Funk, G. Senay, and R. Choularton, 2005: Climate science and famine early warning. Philos. Trans. Roy. Soc. London, 360B, 2155-2168, https://doi.org/10.1098/rstb.2005.1754.

Viste, E., and A. Sorteberg, 2013: Moisture transport into the Ethiopian highlands. Int. J. Climatol., 33, 249-263, https:// doi.org/10.1002/joc.3409.

Vizy, E. K., and K. H. Cook, 2019: Observed relationship between the Turkana low-level jet and boreal summer convection. Climate Dyn., 53, 4037-4058, https://doi.org/10.1007/S00382019-04769-2.

Walker, J. M., S. Bordoni, and T. Schneider, 2015: Interannual variability in the large-scale dynamics of the South Asian summer monsoon. J. Climate, 28, 3731-3750, https://doi.org/ 10.1175/JCLI-D-14-00612.1.

Watterson, I. G., J. Bathols, and C. Heady, 2014: What influences the skill of climate models over the continents? Bull. Amer. Meteor. Soc., 95, 689-700, https://doi.org/10.1175/BAMS-D12-00136.1.

Webster, P. J., and J. Fasullo, 2002: Monsoon: Dynamical theory. Encyclopedia of Atmospheric Sciences, J. Holton and J. A. Curry, Eds., Academic Press, 1370-1385.

Whittleston, D., S. E. Nicholson, A. Schlosser, and D. Entekhabi, 2017: Climate models lack jet-rainfall coupling over West Africa. J. Climate, 30, 4625-4632, https://doi.org/10.1175/ JCLI-D-16-0579.1. 